Illinois State University

ISU ReD: Research and eData

Theses and Dissertations

$5-1-2017$

\title{
Activity Patterns and Division of Labor at a Southeastern Tennessee Late Mississippian Site: Toqua
}

Dustin Lloyd

Illinois State University, djlloyd@ilstu.edu

Follow this and additional works at: https://ir.library.illinoisstate.edu/etd

Part of the Biological and Physical Anthropology Commons

\section{Recommended Citation}

Lloyd, Dustin, "Activity Patterns and Division of Labor at a Southeastern Tennessee Late Mississippian Site: Toqua" (2017). Theses and Dissertations. 761.

https://ir.library.illinoisstate.edu/etd/761

This Thesis is brought to you for free and open access by ISU ReD: Research and eData. It has been accepted for inclusion in Theses and Dissertations by an authorized administrator of ISU ReD: Research and eData. For more information, please contact ISUReD@ilstu.edu. 


\section{ACTIVITY PATTERNS AND DIVISION OF LABOR AT A SOUTHEASTERN TENNESSEE}

\section{LATE MISSISSIPPIAN SITE: TOQUA}

\section{Dustin Lloyd}

\section{Pages}

Entheseal changes (EC), formally musculoskeletal stress markers, are the recordation of osteophytic change at an enthesis (any muscular origin or insertion). Study of EC is valuable in decoding past life activities, social dynamics, and health through the quantification of reactive osseous changes at entheses. The current study assesses EC to ascertain activity patterns at the Late Mississippian Dallas Phase ( 1300-1550 AD) site of Toqua, aboriginally located in the lower Little Tennessee River Valley of East Tennessee. Toqua was a multiple mound, palisaded settlement of maize-intensive agriculturalists. The subsistence strategy may have required intense and possibly specialized labor of the upper arms and shoulders. This study compares entheseal scores of 96 individuals at the origins of biceps brachii, triceps brachii, deltoideus, and pectoralis major on the humerus, radius, and ulna of males $(n=48)$ and females $(n=46)$. These adults are separated into three age-at-death groups: Young Adult (15-30 years of age [yoa]), Middle Adult (31-44 yoa), and Old Adult (45-55+ yoa). The data suggests changes and transitions in social roles or labor patterns as people senesce and tentatively supports a heterarchical social organization. Burial patterns both here and at other Dallas Phase sites and ethnohistoric evidence support this notion. Power relationship within the Dallas phase and at this site may have been more horizontally than vertically complex. This sample does not reflect 
sustained, life-long labor, but rather reflects the heterarchical or fluid social roles and power relationships reflected in the SE Appalachian mortuary patterns and programs.

KEYWORDS: Entheseal Changes, Toqua, Social Bioarchaeology, Division of Labor 


\section{ACTIVITY PATTERNS AND DIVISION OF LABOR AT A SOUTHEASTERN TENNESSEE}

LATE MISSISSIPPIAN SITE: TOQUA

DUSTIN LLOYD

A Thesis Submitted in Partial Fulfillment of the Requirements

for the Degree of

MASTER OF SCIENCE

Department of Sociology and Anthropology

ILLINOIS STATE UNIVERSITY

2017 
(C) 2017 Dustin Lloyd 


\section{ACTIVITY PATTERNS AND DIVISION OF LABOR AT A SOUTHEASTERN TENNESSEE}

LATE MISSISSIPPIAN SITE: TOQUA

\section{DUSTIN LLOYD}

COMMITTEE MEMBERS:

Maria O. Smith, Chair

James Skibo 


\section{ACKNOWLEDGMENTS}

I would like to extend my deepest thanks to all involved in the writing and production of this thesis; however, a few deserve a special acknowledgment. First, I would like to thank the other graduate students in my cohort for the continual support and inspiration as we all strove to keep each other sane and on task. Second, I would like to thank my advisor and mentor, Maria O. Smith, for giving this dirt archaeologist a shot at academia and for her continued support, teaching, knowledge, and patience over the course of the last two years. Third, I would like to thank my family and my mother in particular for her unwavering support of whatever I do and constantly believing I am a better student and person than I believe myself to be. Lastly, I would like to thank the Frank H. McClung for access to their collections, without which this project would not be possible.

D. L. 


\section{CONTENTS}

Page

ACKNOWLEDGMENTS

CONTENTS

TABLES

FIGURES $\quad$ v

CHAPTER I: INTRODUCTION 1

$\begin{array}{ll}\text { Study Parameters } & 2\end{array}$

The Dataset $\quad 3$

CHAPTER II: BACKGROUND

The Mississippian and Dallas Phase Cultural Periods 5

$\begin{array}{ll}\text { Toqua } & 7\end{array}$

CHAPTER III: ENTHESEAL BACKGROUN 11

$\begin{array}{ll}\text { Joint, Tendon, and Ligament Biomechanics } & 11\end{array}$

What is an Enthesis? 12

Factors Affecting Entheseal Biology: Habitual Use, Age, Sex, and Body Size 14

$\begin{array}{ll}\text { Habitual Use } & 14\end{array}$

$\begin{array}{ll}\text { Correlation to Age } & 17\end{array}$

$\begin{array}{ll}\text { Sex and Body Size } & 18\end{array}$

$\begin{array}{ll}\text { Applicability of Entheseal Studies } & 20\end{array}$

CHAPTER IV: METHODS 24

$\begin{array}{ll}\text { Scoring Methodology } & 24\end{array}$

$\begin{array}{ll}\text { Project Methodology } & 27\end{array}$ 
$\begin{array}{ll}\text { Statistical Analysis } & 30\end{array}$

Final Score Calculation Example $\quad 31$

Aging and Sexing Methodology 34

CHAPTER V: RESULTS 36

CHAPTER VI: DISCUSSION

General Trends $\quad 53$

Male Entheseal Patterns $\quad 53$

Female Entheseal Patterns $\quad 55$

Intersex Entheseal Patterns $\quad 56$

Possible Activities at the Site of Toqua $\quad 57$

$\begin{array}{ll}\text { Male Activities } & 57\end{array}$

Correlations between Male Activity and Biological Data 59

$\begin{array}{ll}\text { Female Activities } & 63\end{array}$

Correlations between Female Activity and Biological Data 65

Inter-Individual Variance between Males and Females $\quad 67$

Implications for Patterns within a Heterarchy $\quad 69$

$\begin{array}{ll}\text { CHAPTER VII: CONCLUSION } & 73\end{array}$

$\begin{array}{ll}\text { REFERENCES } & 76\end{array}$ 


\section{TABLES}

Table

Page

1. Scoring Definitions and Degrees of Expression (Henderson et al. 2010, 2015) 29

2. Complete Data for Burial 9

3. Final Mean Scores for Burial 9

4. Average Entheseal Scores by Sex 36

5. Significance of Male and Female Differences across All Age Groups 38

6. Man-Whitney U-Test Sex and Age Group Comparison for Biceps Brachii 39

7. Man-Whitney U-Test Sex and Age Group Comparison for Triceps Brachii 39

8. Man-Whitney U-Test Sex and Age Group Comparison for Pectoralis Major 40

9. Man-Whitney U-Test Sex and Age Group Comparison for Deltoideus 41

10. Z-Score Results for Mound Burials $\quad 52$ 


\section{FIGURES}

Figure

Page

1. Viewshed Analysis of Toqua and Surrounding Sites

2. Artist's Reconstruction of Toqua (As Pictured in the McClung Museum of Natural History and Culture)

3. Scoring Zone of Radial Enthesis of Biceps Brachii (Henderson 2010)

4. Muscle Origin and Insertion for Biceps Brachii, Triceps Brachii, Infrapsinatus, Deltoideus, Pectoralis Major, and Supraspinatus

5. Differences in Mean Entheseal Scores

6. Male Average Entheseal Scores

7. Female Average Entheseal Scores

8. Male Inter-Individual Variance for 15-30 Age Group

9. Female Inter-Individual Variance for 15-30 Age Group

10. Male Inter-Individual Variance for 31-44 Age Group

11. Female Inter-Individual Variance for 31-44 Age Group

12. Male Inter-Individual Variance for 45-55+ Age Group

13. Female Inter-Individual Variance for 45-55+ Age Group

14. Bilateral Male EC Scores

15. Bilateral Female EC Scores 


\section{CHAPTER I: INTRODUCTION}

Archaeologists and anthropologist in general have long been interested in questions of social role or status and division of labor. These questions become especially compelling during the Mississippian period (900 - 1600 AD) as there is evidence for social complexity (e.g., by age and or/sex) that may include stratification and incipient chiefdom organization (Bridges 1989, Franklin et al. 2010, Hudson 1976, Parham 1982, Powell 1988, Sullivan and Harle 2010, Sullivan and Mainfort 2010). Anthropological research in this area typically focuses on the differences in health or access to resources between presumptive elite and non-elite status individuals (Bridges 1989, Havelkova et al. 2011, 2013, Lieverse et al. et al. 2013, Palmer et al. et al 2014, Schrader 2015). A comparison between individuals of different social role or status can be revealing concerning prehistoric social interactions. The comparison can reveal the effects status had on health or resource allocation and availability. Previous research specific to indicators of mechanical stress (e.g. osteoarthritis, enthesopathies [pathological damage to areas of muscle insertion]) has also mainly focused on samples of long term laborers (Galera and Garralda 1993, Havelkova et al. 2011; 2013, Henderson and Cardoso 2013, Milella et al. 2012, Palmer et al. 2014, Schrader 2015, Villotte et al. 2010). Questions of role differences within the Mississippian period by sex, and/or age might be flagged by mechanical stress markers as the time period represents the end result of a dynamic shift in settlement patterns from smaller semisedentary horticulturists groups to larger sedentary agriculturists groups with a variety of social classes, duties, and obligations. 


\section{Study Parameters}

This project will offer a comparative analysis of mechanical stress indicators (entheseal change [EC]) of the shoulder by sex and social role/status (as defined by mortuary treatment) within one large Dallas Phase site in Lower East Tennessee: Toqua (40MR6). The Dallas Phase occurs in the late Mississippian period in Eastern Tennessee from approximately A.D. 13001600 (Schroedl 1998). The site of Toqua was a palisaded aggregate mound center and was occupied continuously during the Dallas phase (Polhemus 1987). Previous research on community health status has indicated that mound interments (eligible by either rank or social role) exhibited better health than the village-interred (Betsinger 2002, Smith 2007, Parham 1987). Previous research has also indicated that clan mothers may be interred in the village (Sullivan 2001). These parameters may frame hypothesized differences in mechanical stress of the shoulder. That is, role or rank may influence the type and nature of manual labor.

The EC data will be used to identify repetitive joint and activity patterns to explore the recent suggestion that Toqua, and Dallas Phase site in general, have a heterarchical power structures (Franklin et al. 2010, Mainfort 2010, Sullivan and Harle 2010, Sullivan and Rodning 2010, Sullivan 2006). Sullivan and Harle (2010) argue, based on ethnohistoric evidence from Cherokee groups and mortuary patterning, that the types of social distinctions and "classes" reflected in mortuary pattern were a difference of degree and not of kind. Social roles were of different types and not based on a hierarchical power or class structure. Power relationship within the Dallas phase and this site may have been more horizontally than vertically complex. They argue that the sphere of interactions at other Mississippian period site like Fain's Island in upper East Tennessee and Ledford Island in lower East Tennessee were of differing kinds rather than of degrees. Sullivan and Mainfort (2010) argue for “...segmentary kinship structures and 
notions of contextualized and overlapping power heterarchies rather than the strict, primarily vertical relations of hierarchies inherent in the chiefdom model.”

\section{The Dataset}

Entheseal change analysis is the documentation and quantification of reactive change at muscle insertions (Hawkey and Merbs 1995, Henderson et al 2006; 2010; 2016, Mariotti et al 2007). An enthesis is the place where a muscle attaches diaphyseally or epiphyseally (Aufderheide 1998, Benjamin et al 2002, Huijing 1998). Indicators of entheseal reactive change (e.g. bone formation, erosion, macroporosity, and fine porosity) that may be reflective of overuse and/or damage (e.g. ligamentous and tendinous tears, or enthesopathies) will be assessed in the Toqua sample at six entheses of the upper arm and elbow: biceps brachii, triceps brachii, supraspinatus, infraspinatus, deltoideus, and pectoralis major. These entheses are important in long term upper limb activity assessments because they are reactive to intense and/or repetitive stress unlike the legs, which incur elevated and nonvoluntary stress. The project compares entheseal scores for 96 individuals at Toqua: 48 males and 46 females. The data will be used to investigate the heterarchical role/status patterns suggested by Sullivan and Harle (2010) and Sullivan and Mainfort (2010) and used to make inferences and conclusion concerning division of labor at Toqua during the Dallas Phase.

The following chapters contain general information about the site, methods, and conclusions concerning my data. Chapter two introduces the site of Toqua and the Dallas Phase more broadly. Chapter three explores joint biomechanics and the correlating factors of entheseal change. Chapter four explains the methods employed to collect the entheseal data. Chapter five presents my data through various charts and graphs. Chapter six explores my inferences and 
conclusion based on the data from chapter four. Chapter seven discusses the border applicability of chapter five's conclusions to the Dallas phase and SE Tennessee archaeology. 


\section{CHAPTER II: BACKGROUND}

\section{The Mississippian and Dallas Phase Cultural Periods}

Mississippian society may be understood through a loose interpretation of the world systems theory of the core-periphery model, which Wallerstein $(1974,2004)$ popularized. The core nation is the most economically diversified, has a strong central government, highly industrialized, and has the tax base to provide infrastructure for a strong economy (Ibid 2004). The periphery nations are characterized by weak governments, small tax base, high percentages of socially disadvantaged people e.g. poor, uneducated, and heavily economically influenced by the core nation (Ibid). Chirot (1986) stated five benefits the core nation receives from periphery domination: access to large quantities of raw material, cheap labor, large profits from direct capital investments, a market for exports, and access to large amounts of skilled labor through migration of people from periphery nations to the core nation. A well-known example of this system was Britain and her colonies.

Mississippian societies may have followed a similar model; however, not all of the above traits may have been present or as emphasized. One key trait present was the redistribution of resources (Cobb 2003, Steponaitis 1991). The heavy focus on agriculture during the Mississippian required a large labor force (Bridges 1989; 1992, Cobb 2003, Pritchard 2009, Sullivan 2001, Woods 2004, Yerkes 2005). Thus, the redistribution of goods took the form of food. Jeske (1999) judiciously cautioned against a strict core-periphery approach. Jeske (1999) suggested four issues concerning utilizing the model to interpret Mississippian life: the difficulty of boundedness of the model, the sparse evidence of a lasting conglomerate core, weak archaeological evidence to suggest elite economic control of resources, and insufficient evidence to demonstrate that elites controlled items in a hierarchical fashion. 
The Dallas phase within the Late Mississippian Period spans the time period of AD 13001550. The phase is named after the Dallas type-site, 40HA1, in lower East Tennessee (Chickamauga Reservoir catchment area). The typical characteristics of the phase can be seen in village sites such as Toqua, which is located on the Little Tennessee River Valley (Polhemus 1987, Schroedl 1998) (v. Fig 1 below from Pardo 2011). The phase reflects the end result of Mississippian trends toward centralized power, increased population density, and incipient chiefdoms (Chapman 1994, Schroedl 1989, Schroedl et al 1990). Sites in this area during the Dallas Phase ranged from larger mound centers to smaller villages, hamlets, or individual homesteads. Current thought states that the larger mound centers exerted control over the smaller villages and hamlets, which resulted in social and political nucleation at a central site such as Toqua (Butler and Welch 2006, Lewis et al 1995, Meyers 2015; 2017, Smith 2003, Sullivan 2001). Permanent year round palisaded villages and a subsistence based on maize agriculture characterized the Dallas phase (Schroedl 1989, Schroedel et al 1990, Sullivan and Prezzano 2001).

The Dallas phase also displays a shift in mortuary patterning. In previous cultural phases, individuals were buried in conical mounds or outside of the village (Schroedl 1998). Some Dallas phase individuals were buried in platform mounds with relatively more and/or exotic grave inclusions within the village (Lewis and Kneberg 1946, Polhemus 1987, Schroedl 1998, Sullivan 2001, 2006). Males and females were also had distinct burial contexts. Sullivan (2001, 2006) and Sullivan and Rodning (2001) suggest that the mortuary patterning at southern Appalachian Mississippian towns are similar to early Cherokee towns. Older females were buried in domestic structures and a subset of males in or near (non-mound) community buildings. Trocolli (2002) and Perdue (1998) cite ethnohistoric records indicating that women 
did hold power as both chiefs and as heads of heads of kin groups. The burial patterns and ethnohistoric evidence suggest that men may have acted and held more power within public or social domains and woman within domestic and private domains.

\section{Toqua}

Toqua (40MR6) is an important archaeological site located in southeastern Tennessee in Monroe County, and has been excavated three times (Chapman 1985, Polhemus 1987). J.W. Emmert first dug the site in 1884. A treasure hunter, George Barnes, followed him. He excavated the plaza and recovered many burials, which were subsequently discarded. Then, in 1967, the University of Tennessee's Department of Anthropology began survey in the area because of the impending Tellico Dam project, which flooded the river valley and the site of Toqua. Toqua was a thriving Mississippian village located near the confluence of the Little Tennessee and Tennessee Rivers and was arguably a major Mississippian polity throughout the Dallas Phase. It is theorized that it held a political, economic, and/or religious alliance with the other contemporary major cultural centers Citico, Bussell Island, and Tellico Plains (Chapman 1985). My recent viewshed assessment and least cost path analysis support Chapman's (Ibid) notion. Toqua has the largest contiguous viewshed of the river valley, all the most optimal cost efficient paths between the four sites cross through Toqua. All of this compounded with its central placement in the Little Tennessee River valley support the hypothesis that it was an important site with sociopolitical connections to the above-mentioned sites. 
Toqua, Bussel Island, and Tellico Viewsheds
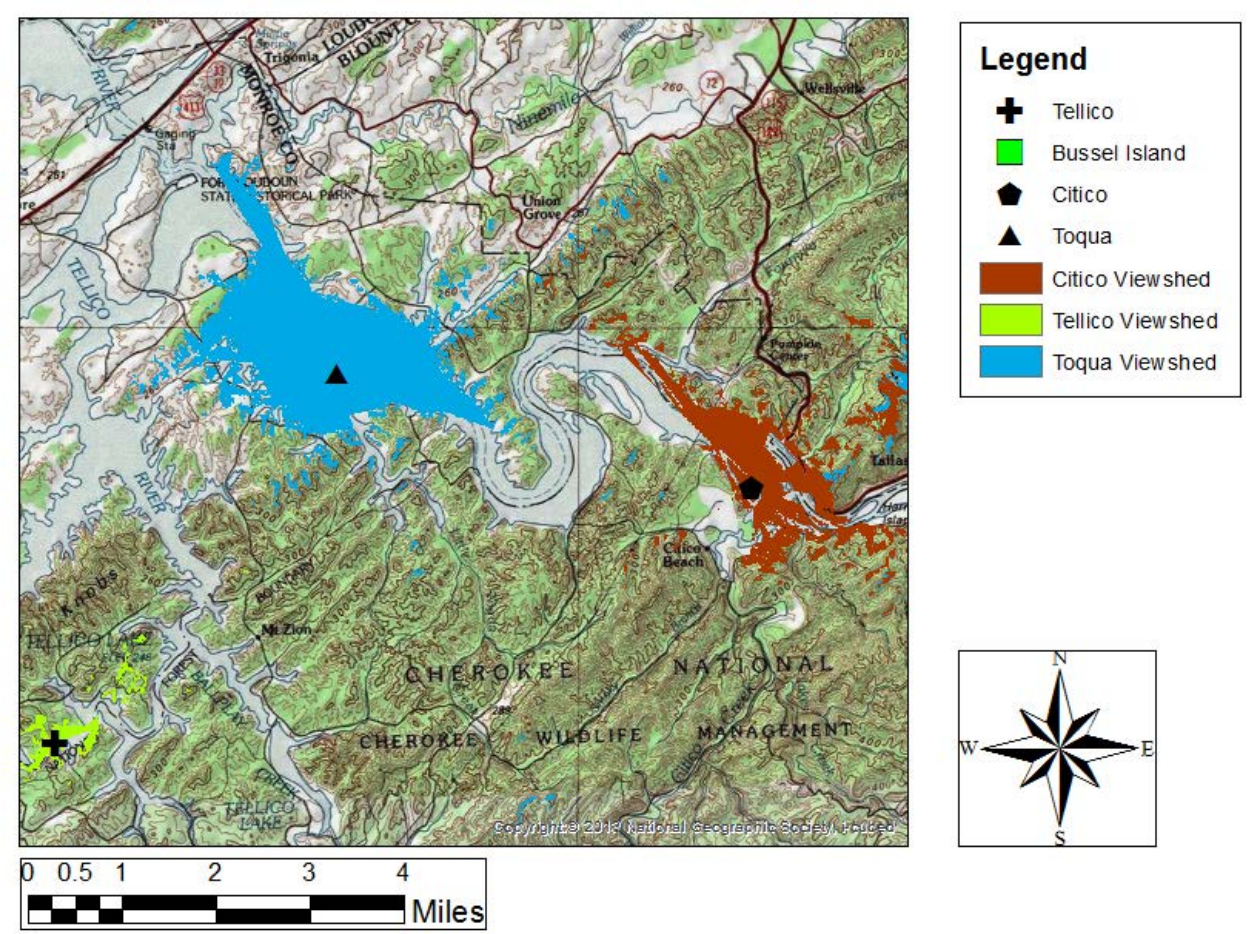

Figure 1. Viewshed analysis of Toqua and surrounding sites

The village was dominated by two large earthen mounds. Mound A, the largest, was constructed over a period of 250 to 300 years and in multiple phases (Polhemus 1987). The mound shows evidence of 15 construction phases (Ibid 1985). Four structures were found on top of the mound: two on the west and two on the east. The two western structures were unequal in size. The larger was theorized as a meeting place for political or religious affairs (Ibid 1985). The smaller western structure appears to be a house. Fire also occurred on the mound during phase eight of the building and burned down the residential structure killing its occupant. A similar incidence also happened during phase 11 . During the end building phases, several individuals 
were buried in the mound. The 1884 excavation by J.W. Emmert recovered 57 human remains from Mound A.

Mound B is located 200 feet south of Mound A. Mound B is a large platform mound measuring 93 feet in diameter and six feet high. Extensive modern farming and plowing has reduced the mound to a slight rise. Modern farming and previous archaeological excavations have somewhat obscured the building sequence of Mound B; however, there were two structures on this mound. The larger of the two burned down and a large earthen platform was constructed following the fire. Numerous burials occurred in this mound. Chapman (1985) theorizes that the structure and mound may had some mortuary importance based on the presence of exotic grave goods with many of the mound burials. Whatever the purpose of the mound and structure, both had great cultural significance since all of the palisade remodels enclosed the mound. Fourteen burials were recovered from Mound B. 


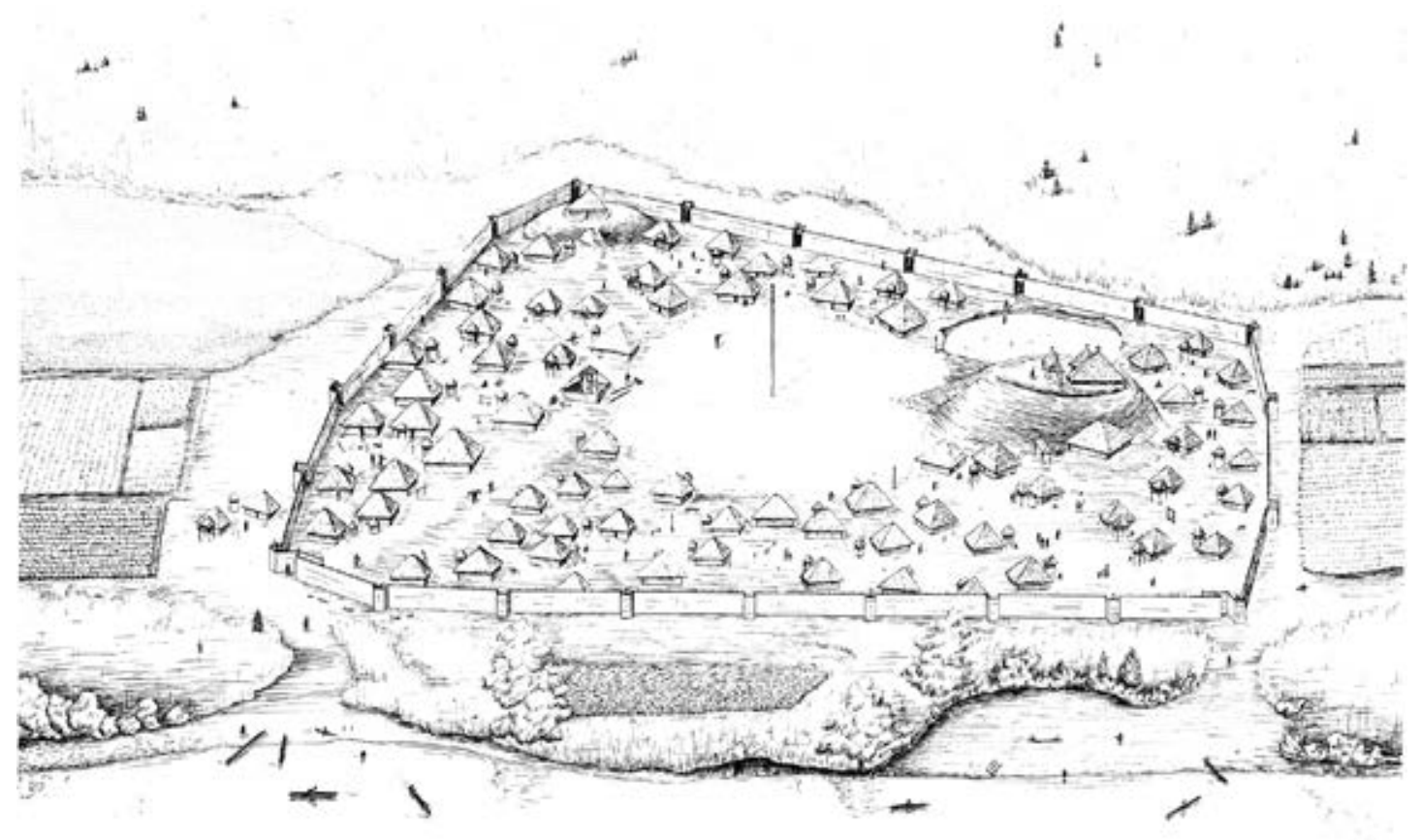

Figure 2. Artist's reconstruction of Toqua (as pictured in the McClung Museum of Natural History and Culture)

As typical of many Mississippian settlements (Cobb and Butler 2016, Lewis et al 1998, Sullivan et al 2010), a plaza was located between the two mounds. This plaza served as a focal point for secular and ceremonial life. A residential area flanked and surrounded the plaza. Burials were also recovered from residences since typical Mississippian burial pattern was to bury the dead in or near the house. George Barnes excavated the plaza area in the 1930s and found an additional 100-150 burials, which were subsequently, unfortunately not curated (Polhemus 1987). 


\section{CHAPTER III: ENTHESEAL BACKGROUN}

\section{Joint, Tendon, and Ligament Biomechanics}

Bone and joint tissues have similar biomechanical properties (Benjamin et al. 1986; 2002). Both are malleable substances, which have well defined elastic limits called elastic moduli. Joints, like bones, have a dynamic response system to mechanical stress (Benjamin 1998, Khan and Cook 2000, Hirashima et al. 2010, Lieber and Friden 2000). Osteons and myocollagen fiber are able to "sense" stress placed on them and respond to the loading pressure (Nordin and Frankel 2001). Joint tissues (extracellular matrix, ground substance, and elastin) are also able to repair themselves similar to how osteons repair and restructure injured bone in response to mechanical loading pressure.

Tendons contain three elements: extracellular matrix (ECM), ground substance, and elastin. ECM accounts for around 80\% of the connective tissue. ECM is a collection of extracellular molecules, which are secreted by the surrounding cells to provide structural and biomechanical support for the surrounding cells. ECM is found in a variety of contexts outside of joint bodies. Ground substance consists of aggregated proteoglycans, which assist in the binding of the ECM and coalesce the ECM into a gel like material. The proteoglycan and ECM mixture provides structural support to the surrounding cell bodies (Nordin and Frankel 2001). Elastin makes up about 2\% of the matrix; however, it provides flexibility for the joint body.

Bone and joint material are strong in different ways. Bone is strongest in compression, weaker in tension, and weakest in shear. Joints are strongest in tension, weaker in compression, and weakest in shear (Schlecht 2012). The varying strengths and weaknesses of bone and joint tissue necessitate an intermediary structure: the enthesis. 


\section{What is an Enthesis?}

Benjamin et al (2002:931) defined an ethesis as, “...the region where a tendon, ligament or joint capsule attaches to bone”. Entheses also ensure that the contractile forces of the muscle is transmitted to the bone and movement occurs. Entheses also dissipate the differing elastic moduli of tendons and skeletal tissues so that local peaks in stress do not result in injury. The fundamental structure of an enthesis stresses a general engineering principle: the most stress will be placed at the interface of two differing material types or mechanical properties (Ibid). An enthesis' most imperative job is to dissipate stress down the attachment site into the surround tendons and bony matrix. The enthesis does this by promoting shear across the interface rather than direct stress of a tensile load (Huijing 1999). Despite the mechanical marvel of an enthesis, mechanical injuries are common, such as tennis elbow, jumper's knee. An injury of this type is an enthesopathy (Benjamin et al. 2002, Maier et al. 2001, Nirschl, 1995).

An enthesis comes in two types: fibrous and fibrocartilaginous (Benjamin et al. 2002, Benjamin and Ralph 1995; 1997, Knese and Biermann 1958). Entheses are divided into two groups based on the type of connective tissue at the bone-tendon interface: fibrous connective tissue vs. fibrocartilaginous tissue. Benjamin et al (1986) classified fibrous entheses as attachments along the diaphysis of a bone and fibrocartilaginous as attachments near epiphyses. Fibrous entheses also, generally, attach via the periosteum. Fibrocartilaginous entheses generally display a chondro-epiphyseal attachment. Further complicating the issue, some entheses begin as fibrous and become fibrocartilaginous or contain histological elements of both types.

A fibrous enthesis has two attachment patterns: periosteal and bony (Benjamin et al 2002). In a periosteal attachment, the enthesis manipulates the bone and dissipates mechanical stress through a connection at the periosteum through Sharpey’s fibers. Sharpey’s fibers are a 
type of perforating, chondral fiber that attaches both the periosteum to the bone and the enthesis to the periosteum. In a bony attachment, the tendon inserts directly into the bone itself. A bony attachment occurs with age in some periosteal attachments. The periosteum breaks down and the tendon attaches at the bone. Hems and Tillmann (2000) have shown that some fibrous entheses remain periosteal throughout life in some mastication muscles.

A fibrocartilaginous enthesis has four distinct histological zones: dense fibrous connective tissue, uncalcified fibrocartilage (UF), calcified fibrocartilage (CF), and bone (Benjamin et al. 2002, Biermann 1957). There is no periosteum at this type of attachment. The tendon inserts into the bone via the previous four zones. The dense connective tissue is diffuse in the human body and serves many purposes to connect skeletal elements, and encapsulate muscles and some joints. The connective tissue serves a similar purpose here by providing an anchor point for initial tendon attachment. The UF and CF are avascular zones that are separated by a basophilic line called a tidemark (Benjamin et al 2002). The tidemark serves as the mechanical boundary between hard and soft tissue. The collagen of the tendon continues past the tidemark at a right angle. The tendon does this to obey the general engineering principle above. Attaching at a 90-degree angle minimizes stress at the tidemark.

Both types of entheses are visible on dry bone (Bannister et al. 1995,Benjamin et al 2002). The various ridges, tubercles, and trochanters that bone displays are the marker for origin and insertion of muscles. The different types of entheses present different markers on the bone. A fibrocartilaginous attachment displays a smooth, well circumscribed border around the insertion or origin. The attachment area is also lacking any evidence of vascular foramina since it is not attached at the periosteum e.g. popliteus tendon. A periosteal attachment also may present a smooth attachment area; however, the area is more diffuse and amorphous relative to a 
fibrocartilaginous attachment. Periosteal attachments often display rugose ridges or diffuse roughened areas e.g. deltoid tuberosity or inferior temporal lines.

The analysis of this project will concern fibrocartilaginous entheses, with the exception of the diaphyseal attachment of the deltoideus, since their borders are more recognizable and less prone to scoring errors. The scoring methods employed will generally follow the methods laid out by Henderson and her colleagues (2010, 2012, 2015). Slight modifications were made to their scoring protocol and are explained below.

\section{Factors Affecting Entheseal Biology: Habitual Use, Age, Sex, and Body Size}

Anthropologists and archaeologists have long assumed that morphological changes and developments at entheses are in response to biomechanical loading or habitual activity (Kennedy 1983, Hawkey and Merbs 1995, Peterson 1998, Cook and Dougherty 2001, Palmer et al. et al 2014, Schrader 2015). However, the complex relationship between biomechanical stress, habitual use, age, sex, body size, and genetics is more complex than first thought. All of the above factors have been shown to affect and to correlate significantly with EC scores. Biomechanical stress and habitual use play a role in entheseal development; however, researchers must attend to the above factors to produce holistic data with the ability to solve problems and to answer questions.

\section{Habitual Use}

Biomechanical stress seems to be the logical cause of entheseal development and change based on knowledge of normal bone remodeling (Frost 1994, 2003, Ruff et al 2006). Larger muscles, gained through habitual use, apply stronger and larger tensile loads to attachments sites. Bone's response is skeletal hyperostosis. Bone requires a larger enthesis to dissipate better the additional stress of a larger muscle. Therefore, a larger enthesis is more advantageous than a 
smaller enthesis since it will dissipate stress better than a smaller enthesis. A larger enthesis also allows for stress to be proportional in each square unit of measurement on the bone, which reduces the tensile effects of the muscle belly on insertion sites (Zumwalt 2006). Two studies conducted on mice call this logical thought process into question (Hamrick et al. 2000, Montgomery et al. 2005). Both studies involve the effects of myostatin and dystrophin in mice. Myostatin is a chemical that stops myogenesis, production of new muscle, and dystrophin is a chemical that produces key connective fibers necessary at muscle attachment sites. In both studies, one group of mice received the chemicals and the control group was not given any drugs. Neither group of mice exercised in any abnormal ways. Both studies found entheseal size to correlate to muscle and body size meaning that entheseal development may not be intrinsically linked to biomechanical stress and may be linked to overall muscle size and not directly to usage. Myofiber proliferation may have a more direct connection to entheseal development rather than biomechanical stress.

Zumwalt (2006) undertook a very interesting study involving sheep to test the relationship between normal physical activity and entheseal development. He used a group of 20 female sheep. All sheep were approximately four years old. Sheep typically live about 10-12 years so, in human terms, these sheep are about 30-35 years old. He trained 10 of them to run on a treadmill for one hour, five days a week for 90 days. The other sheep served as the control and only partook in normal activities. At the end of the 90 days, the sheep were euthanized. He analyzed six different entheses utilizing a 3D digital scanner. He separated each enthesis into various zones to compare and contrast different zonal development between the two ovine groups. He found very little difference between the two sheep groups. His findings suggest that entheseal development may not be linked to muscle size or usage. There are some caveats to 
consider from his research. He tested on skeletally mature sheep. The macro structures of bone are much more malleable in the young (Ruff et al. 2006). Perhaps noticeable change would occur if this experiment had a comparative younger group. Also, while animal studies are wonderful for experimental research, they do not always mirror human populations. In an animal experiment, the observer has much more control over the subjects than in a human trial. Many other animal groups display biological osseous mechanisms, which are similar to humans; however, key differences exist between our skeletal biology beyond the obvious quadruped configuration. Humans have a much longer period of skeletal development. Human skeletons experience larger amounts of stress due to our flexible limb pattern and much longer life spans (Schlecht 2012). Lastly, smaller mammals do not employ Haversian remodeling strategies to the degree that humans do (Ibid).

The above results also question thoughts concerning habitual use. An enthesis' major role is to protect the osteotendinous interface and to dissipate stress away from the joint and down into the cortical bone. Therefore, an enthesis may be designed not to allow stress above a certain remodeling threshold and relocate any additional stress to the cortical bone. Frost’s (2003) mechanostat provides a negative feed loop explanation to understand bone’s ability to detect and respond to stress stimuli. Bone growth and bone loss is stimulated by the local mechanical elastic deformation of bone. The reason for the elastic deformation of bone is related to the forces caused by muscles. The adaptation (feed-back control loop) of bone according to the maximum forces is a lifelong process. Bone adapts its mechanical properties according to the needed mechanical function. Bone mass, bone geometry, and bone strength is adapted according to the everyday usage and needs. Therefore, if entheses were to respond to habitual stress through periosteal remodeling then the stress would have to be above the normal remodeling thresholds 
(Schlecht 2012). Frost's theory questions the older theories of habitual use. Older models (Hawkey and Merbs 1995) state that the genesis of entheseal remodeling is accumulated microtrauma from habitual use. Newer data (Frost 2003, Schlecht 2012) suggests that the remodeling may be a response to acute mechanical loads, which surpassed established remodeling responses and could not be dissipated fully into the cortical bone requiring periosteal and entheseal modification. Additionally, Wolff (1986) proposed a general law concerning osteophytic response to stress, which said that bone will adapt to the loading pressures applied to it. His law applies inversely as well. If a person stops habitually loading muscles and stressing entheses, then his or her entheses will begin to dissipate in response to the decrease in stress.

\section{Correlation to Age}

Age is most commonly found to correlate significantly with higher EC scores no matter the employed method (Galera and Garralda 1993, Hawkey and Merbs 1995, Henderson et al 2012 Lieverse et al. 2013, Mariotti et al 2007, Milela 2012, Weiss 2003, Villotte et al. et al 2010, 2013). The broader question is why age is so highly correlated with increasing EC score. Following the above argument, if an individual's normal daily activities decrease with their remodeling threshold then EC may be more indicative of periosteal degradation around insertion sites because the bulk of the stress would have been dissipated into the cortical bone. Therefore, EC may be a geriatric response to a lifetime of periosteal wear and degradation, which is why EC correlates highly with age; however, this conclusion may be confounded in an archaeological sample since exact age and occupational history cannot be assessed as accurately has a historical sample. Various studies (Cardoso 2010, Milela 2012, Weiss 2003, Henderson 2013) used modern historic cemetery in which age at death was known to the year. Their studies came to the same age related correlation. 
The methodology outlined by Weiss (2003) is of particular interest. She attempted to control for three main variables: age, body size, and long bone robusticity. She found that all three variables correlated at differentiating levels of significance to EC; however, age was the best predictor of entheseal development. Her results indicate that there is a strong link between EC, age, body size, and long bone robusticity. She also encourages researchers to aggregate known working groups of muscles and their associated entheses to gain a better overall look into how past people utilized muscle groups. Composite scoring of this type is useful to infer possible types of actions that people may have done in the past.

\section{Sex and Body Size}

Sex and body size are also variables to consider. The biomechanical stress arguments discussed above can be applied to these issues as well. If entheseal development may have a stronger link to myofiber proliferation, then sex and body size further conflate the issues of data validity for EC scores. The differences often noted between sexes (Palmer et al. et al 2014, Milela 2012, Galera and Garralda 1993, Havelkova et al. 2011 and 2013) may be due to the sexual dimorphic muscular and body size differences between males and females and may not be strictly caused by sexual division of labor. Males, on average, are bigger than females. The higher EC scores may represent natural sexual dimorphism and not sexual division of labor or increased and more strenuous labor in a particular sex (Schlecht 2012).

Researchers such as Schlecht (2012) suggest that entheses may not be the only place to look for past activity reconstruction. An enthesis' major job is to dissipate stress away from the joint body and down into the surrounding cortical bone. Therefore, he suggests that the answers researcher seek may be in the cortical bone. He suggests a dry bone histomorphometric analysis of osteon population densities (OPD) surrounding entheses. OPD shows the history of bone 
remodeling, which exceeded the individual's prescribed remodeling threshold. He bases this claim on the premise, “...that osteonal remodeling event is initiated by the emergence of microdamage, then the activation frequency of these events should be proportional to the rate of fatigue damage in individuals...” (Ibid: 1247). Bone would then maintain its structural integrity by the activation of multicellular response units relative to the mechanical stress. His theory is based on Frost's (1990) concept that an inverse relationship exists between osteon size and the magnitude of stress applied. As osteons undergo stress, they are deboned and need to be replaced. The body attempts to counter future stress and deboning by decreasing the cutting cone of osteoclasts (cells responsible for bone maintenance, repair, and remodel). The body does this because the smaller the osteon are the more cement lines (cell walls of osteon) the incoming stress must encounter. Thus, smaller osteons create a higher density of osteons in particular areas and are able to dissipate greater mechanical loads with smaller osteon loss. Skedros et al (2001) conducted a study on Artiodactyla calcanei and showed that larger osteons were more prevalent in areas of lower stress as opposed to areas surrounding tendon insertion. If OPD studies on human remains conclude results similar to Skedros et al (2001) on or near entheses, then macroscopic assessment of entheseal development would have additional support.

In the presence of all this evidence, a complex relationship exists between entheseal development and various social, biological, and cultural factors. The relationship becomes more complex since bone is not mono-responsive; no population responds to stress the same as another. People in different times and place respond to stress in differing ways. The current study attempts to understand osteophytic and osteolytic responses of people within the Dallas Phase at Toqua and explore cultural explanations to their osseous reactions. 


\section{Applicability of Entheseal Studies}

In light of the above research, how does bioarchaeology reconstruct of past activity? Past activity reconstructions need to expand their horizons in a number of ways. Reconstructions and those who reconstruct need to apply concepts that are not only driven by an activity, mechanical stress, or habitual use mindset. "The future of bioarchaeological research is one filled with new opportunities. The path, however, will require new approaches and broader expertise. The old assumptions leading to an 'activity-only' mindset are no longer tenable” (Jurmain et al. 2012: 545). Bioarchaeology can accomplish this high task by engaging in interdisciplinary studies with skeletal biologists to broaden their skill sets and to engage with the molecular, regulatory mechanisms influencing phenotypic displays on bone and incorporating a sociobiological lens into their interpretations.

Skeletal biologists have information concerning the biomechanical mechanism of wet bone that will inform future study of dry bone. Collaborative efforts with sports or occupational sciences are useful as well (Jurmain et al. 2012). Many of these studies (some discussed below) offer interesting insights into modern populations and the effects of activities on cortical bone. Other important work is the methodological and etiological work of Henderson et al (2010). Her work on known age at death, sex, and occupation cemeteries may well provide seriation data important to entheseal development, geriatric entheseal changes, or how activity patterns influence EC. Two steps can be taken to bridge the gap between archaeological activity reconstructions and clinical or biological perspectives: interdisciplinary cooperation between bioarchaeologists, skeletal biologist, sports/occupation medicine practitioners, and geneticists; and the injection of cultural context through the implementation of the biosocial approach. 
One avenue of research that has proven to be informative is cross sectional bone geometry (CSBG). CSBG is analysis of cortical bone in cross section. It was popularized as an approach to study locomotion in hominids (Lovejoy and Trinkaus 1980, Ruff 2009). CSBG has a more clearly empirical approach than EC (Jurmain et al 2012). The technique has been employed in various archaeological contexts (Bridges 1989, Maggiano et al 2008, Sladek et al 2007, Weiss 2009) to a variety of results. Some (Maggiano et al 2008) reported only general types of activity reconstruction, while others (Sladek et al 2007, Weiss 2009) reported much more exact activity reconstructions. Other studies have also looked at the cortical bone of athletes (Emslander et al 1998, Heinoen et al 2002). The research of Shaw and Stock (2009a, b) produced some promising results, which should encourage collaborative efforts between bioarchaeology and sports medicine. Their results on upper and lower limb patterning suggest CSBG as a solid basis to interpret at least some aspects of past activity. They found that habitual activities such as throwing, swimming, and running, have significantly correlated to diaphyseal strength and morphology of the studied athletes relative to a control group. One must remember that bone geometry is much more pliable in younger groups (Pearson and Lieberman 2004). Thus, it is not surprising that younger populations provide the most definitive results. The mean age that training started in the Shaw and Stock (2009a, b) experiments was between 9.5 and 13.7 years. Many agree with Pearson and Lieberman (2004) that cortical morphology may be the result of skeletal loading pressures during adolescence.

Another avenue of bridging the gap is through the injection of culture to contextualize data. Culture is the key to unraveling the mysteries of how and why people acted during life. Culture must be a key component in any pertinent and informed activity reconstruction. Recent examples of this trend is the work by Schrader (2015) and Palmer et al. et al (2014). 
Schrader (2015) makes use of the archaeological data to confirm inferences of social status between two archaeological defined burial groups at the site of Kerma in Sudan. One group was buried closer to the king and another was on the periphery. The archaeological analysis suggested that the inner group had closer political or social ties to the king and most likely represented an upper echelon of social class as compared to the periphery burials. EC data proved those theories correct. The EC scores for the inner group were much lower than the periphery group, suggesting that the latter was involved in more physical activity. The periphery group also demonstrated a localized spike in EC in the lower back and hip. She attributes this spike to the hard work of the agropastoral lifestyle, which is also archaeologically verified for the period.

Palmer et al. (2014) examines the remains from a 19th century Dutch cemetery in Middenbeemster. They also have a very good archaeological context to utilize. The city was centered around dairy and crop farming. There was also evidence for a higher class that presumably did less work than the harder laboring farmers did. They use this context to ask questions of status and stratification. They found that a vast majority of the population participated in heavy manual labor based on the high prevalence of osteoarthritis (OA) and EC, and left side asymmetry of OA and EC. The asymmetry is important since in activities requiring excessive force a right handed person would apply the force with the left hand and direct the force with the right hand. They also found that men had higher scores for biceps brachii and women had higher scores for triceps brachii. They conclude a possible sexual division of labor. Women more frequently engaged in activities involving pulling with a bent elbow as in milking a cow or scrubbing laundry on a board. Men more frequently engaged in activities that required lifting of heavy objects or application of heavy force like bailing hail or carry full baskets. 
All of the above data on etiological concerns shows that bioarcheology cannot conflate low intra- and interobserver error with successful reconstructions. Past activity reconstructions need to incorporate osteobiological data into their conclusions and inferences. Conclusions and inferences also need to be tempered with a sociobiological approach. Biology and culture are intrinsically intertwined. The methodology and biological research employed in this study attempts to reconstruct social and activity based aspects of people at Toqua by incorporating their biology (entheseal changes) and culture (social and power structures).

The holy grail of activity reconstruction is within bioarchaeology's grasp (Jurmain et al 2012). Researchers owe it not only to themselves but more importantly to the people they study to seek out and to use the most advanced methodologies and biological knowledge. By being good stewards of the past, bioarchaeology is able to paint pertinent pictures of past activity through the utilization of the most current cultural and biological data. Culture is the integral mitigating factor between the biological and bioarchaeological perspectives and knowledge. Collaborative efforts between sports and occupation scientists and bioarchaeologist will produce synthetic and accurate pictures of how past peoples conducted and socially structured themselves. 


\section{CHAPTER IV: METHODS}

\section{Scoring Methodology}

The Henderson et al method (2010) came from a small working group at a workshop and conference in Coimbra, Portugal in 2009. The conference focused on musculoskeletal stress markers and their uses in reconstructing past activity. Henderson and her colleagues attempted to construct a standardized data collection method for EC. There method is one of the newest attempts at quantifying EC data. It splits the enthesis into two zones: Zone $1=$ the margin opposite the acute angle of muscle insertion, Zone 2 = Remaining margin and surface of insertion. Zone 1 is scored for bone formation (BF Z1) and erosion (ER Z1). Zone 2 is scored for bone formation (BF), erosion (ER), fine porosity (FPO), macro-porosity (MPO), and cavitation (CA). An example of Zone 1 and Zone 2 for the biceps brachii is shown (Figure 4.1). The black outline is the margin or Zone 1 and the grey area is Zone 2. 


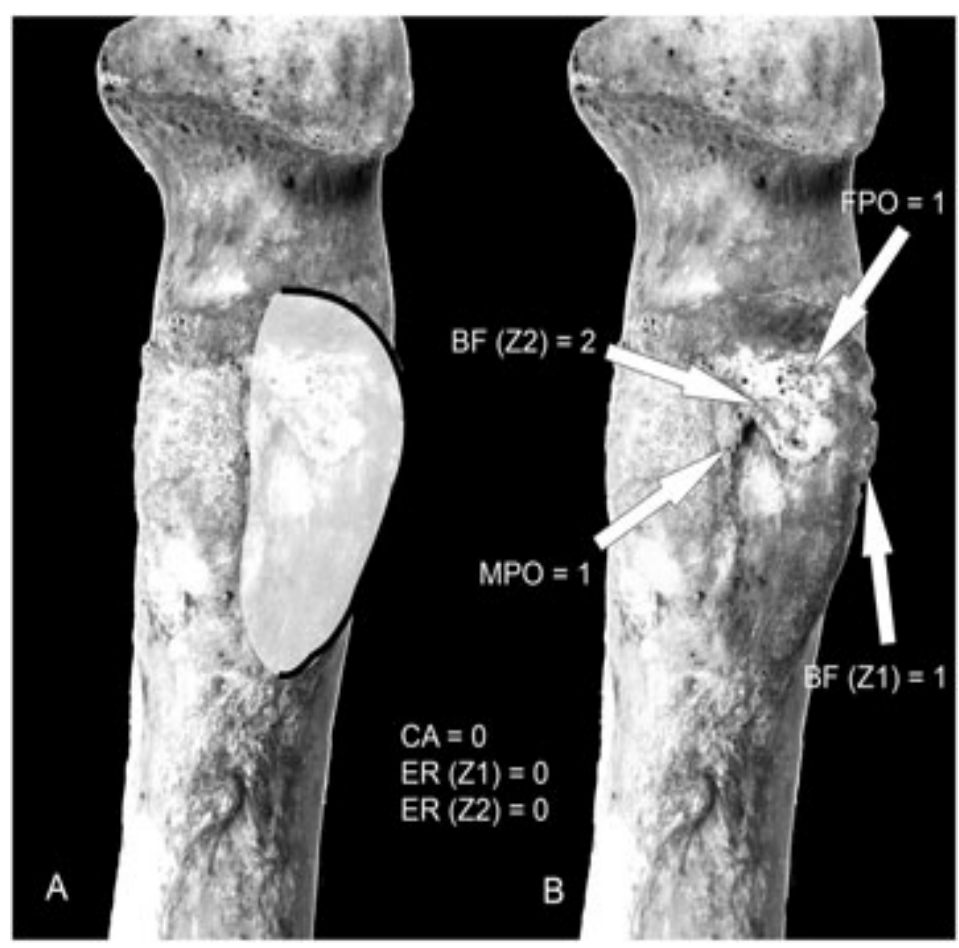

Figure 3. Scoring zone of radial enthesis of Biceps Brachii

(Henderson 2010)

This method excels at quantifying the types of reactive changes on an entheses for a number of reasons. Henderson et al (2012) suggest that a labeling of processes or reactive changes within the suite of changes may provide more information on the age correlation that the other methods anecdotally note (Hawkey and Merbs 1995, Mariotti 2007). Their method allows for the collection of data, which can differentiate the types of changes in different age groups. The authors found that bone formation seemed to be closely correlated with age, which makes sense since an older individual would have more opportunity to incur microtrauma resulting in increased bone formation; however, their sample was small so this may not hold true for a larger 
sample. The wide array of features recorded helps to diversify the data so that researchers can ask more complex questions since activity patterns are easier to recreate.

Their method also has some weaknesses. Issues of reproducibility and the systematic disagreement between two of the observers are the major problems. The authors attribute this to each observer's previous creation of their own scoring protocol. Again, their disagreement speaks to the larger issue of lack of standardized scoring methods. That withstanding, a systematic disagreement between the same observers may point to a programmatic flaw in their method. The authors suggest an accompanying picture compendium, which outlines what each scoring degree resembles. Some, FPO and MPO, have rather banal scoring protocol, which is easy to understand, Others, BF and ER, have more enigmatic and diffuse scoring measures, which rely on the observer's judgement. The addition of pictures strengthened Mariotti et al's (2007) method and it may do the same for this method and should decrease their inter- and intraobserver error.

Overall, their error is close to acceptable ranges; however, on some entheses it ranges from $30-40 \%$, which is unacceptable. One solution is to decrease the range of scoring degrees. Decreasing options will decrease the error; however, it will also lead to a loss in data. Three scoring options, seems to be optimal. Three degrees encompasses the extremes and middle option. Combination of the middle and upper extreme or middle and lower extreme would lead to data loss and possibly more confusion as the definitions would become more ambiguous and opaque. A recent study (Lloyd 2016) on the pre-Columbian Illinois sample of Schroeder Mounds (11He177) explored the impacts of retaining three collection options, while updating the definitions to the 2015 standard and integrating a picture reference guide to aid scores. I found that the picture guide was more useful for initial scoring or new users of the system. Their 
(Henderson et al 2015) updated system with less scoring options was an attempt to standardized their system and further explore the osteological origin of entheseal change (personal communication Henderson 2016). The current project is not concerned with those questions, but with more nuanced data collection. Therefore, this project uses a slightly modified Henderson et al scoring methodology.

\section{Project Methodology}

The scoring definitions mirror the work of Henderson et al. (2015) and the scoring degrees came from their 2012 publication (Table 4.1). However, the definition of cavitation makes macroscopic identification and photography difficult since the opening must be smaller than the subcortical cavity. Cavitation was also not scored since no quantifiable examples existed in the Schroeder Mounds test sample, which made it difficult to ascertain the usefulness of the picture reference guide for those scoring categories. Textural change was not recorded since it is scored on a presence or absence basis, which is not a robust enough scoring protocol. As such, cavitation and the present research does not score cavitation or textural change.

This project collected entheseal data for six entheses group of the upper arm and shoulder: biceps brachii (long head insertion and origin), triceps brachii (long, lateral, and medial origins and insertion), infraspinatus (origin and insertion), supraspinatus (origin and insertion), deltoideus (anterior, lateral, and medial origins and insertion), and pectoralis major (origin and insertion) (Figure 4.2). Additionally, Zone 2 was expanded for pectoralis major to include the costoclavicular and capsular ligament, which were also checked for enthesopathy, trauma, or pathological injuries. Zone 2 was also expanded for deltoideus anterior to include the inferior acromioclavicular ligament and trapezoid ligament, which were also checked for enthesopathy, 
trauma, and pathological injuries. All other Zone 1 and 2 assignments followed the Henderson et al method (2010, 2012, 2015).

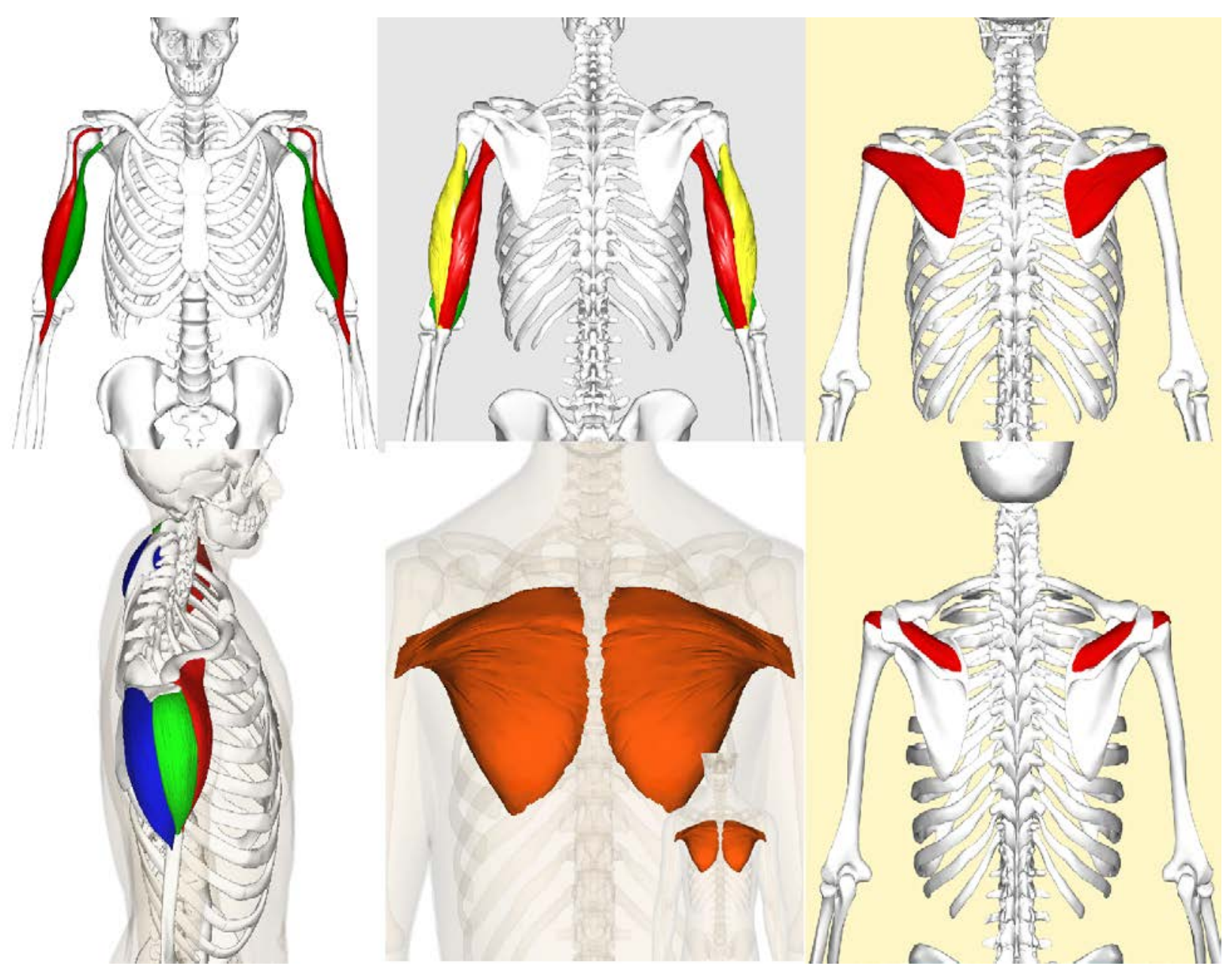

Figure 4. Muscle origin and insertion for Biceps Brachii, Triceps Brachii, Infrapsinatus, Deltoideus, Pectoralis Major, and Supraspinatus. Muscles listed from left to right and top to bottom. Source: Body Parts 3D/Anatomography (http://lifesciencedb.jp/bp3d/?lng=en) 
Table 1

Scoring Definitions and Degrees of Expression (Henderson et al. 2010, 2015).

\begin{tabular}{|c|c|c|}
\hline & Scoring Feature & Degree of Expression \\
\hline \multirow[t]{2}{*}{$\begin{array}{l}\text { Zone 1: Margin opposite } \\
\text { acute angle of fiber } \\
\text { attachment }\end{array}$} & $\begin{array}{l}\text { Bone Formation (BFZ1): } \\
\text { See degrees of } \\
\text { expression. Normal } \\
\text { morphological smooth- } \\
\text { rounded or mound-like } \\
\text { (check by touching) } \\
\text { margins, even if the } \\
\text { margin is elevated, } \\
\text { should be scored as } 0 \text {. }\end{array}$ & $\begin{array}{l}1=\text { small, nodular or slightly raised } \\
\text { margin }<1 \mathrm{~mm} \\
2=\text { distinctive, sharp crests or other } \\
\text { enthesophytes } \geq 1 \mathrm{~mm} \text { but }<50 \% \text { of } \\
\text { margin } \\
3=\text { distinctive, sharp crests or other } \\
\text { enthesophytes } \geq 1 \mathrm{~mm} \text { but } \geq 50 \% \text { of } \\
\text { margin }\end{array}$ \\
\hline & $\begin{array}{l}\text { Erosion (ERZ1): } \\
\text { Depression or } \\
\text { excavations of any shape } \\
\text { and involving } \\
\text { discontinuity of the } \\
\text { lesion greater in width } \\
\text { and depth with irregular } \\
\text { margins. Only erosions } \\
>1 \text { mm where you can } \\
\text { clearly see the floor, } \\
\text { were recorded. This does } \\
\text { not include pores } \\
\text { (rounded margins). Score } \\
\text { erosions if they occur on } \\
\text { bone formation. }\end{array}$ & $\begin{array}{l}1=<25 \% \text { margin } \\
2=25 \text { to } 50 \% \text { margin } \\
3=>50 \% \text { of margin }\end{array}$ \\
\hline $\begin{array}{l}\text { Zone 2: Remaining } \\
\text { margin and surface }\end{array}$ & $\begin{array}{l}\text { Bone Formation (BFZ2): } \\
\text { Any bone production } \\
\text { from roughness of } \\
\text { surface to true exostoses } \\
\text { (e.g. distinct bone } \\
\text { projections of any form, } \\
\text { like bony spurs, bone } \\
\text { nodules, and amorphous } \\
\text { bone formation). }\end{array}$ & $\begin{array}{l}1=\text { roughness/rugosity change is } \\
\text { diffuse not a distinct structure } \\
2=\text { distinct structure measuring }>1 \\
\text { mm, affecting }<50 \% \text { of surface } \\
3=\text { distinct structure measuring }>1 \\
\text { mm, affecting } \geq 50 \% \text { of surface }\end{array}$ \\
\hline
\end{tabular}

(Table Continues) 


\begin{tabular}{|l|l|l|}
\hline $\begin{array}{l}\text { Zone 2: Remaining } \\
\text { margin and surface }\end{array}$ & $\begin{array}{l}\text { Fine Porosity (FPO): } \\
\text { Small, round to oval } \\
\text { perforations with smooth, } \\
\text { rounded margins }<1 \\
\text { mm. These should be } \\
\text { visible to the naked eye } \\
\text { and be in a localized } \\
\text { area. Do not score if they } \\
\text { are at the base of an } \\
\text { erosion of if they occur } \\
\text { as part of woven bone. }\end{array}$ & \\
\hline & $\begin{array}{l}\text { Macroporosity (MPO): } \\
\text { Small, round to oval }\end{array}$ & \\
\hline & $\begin{array}{l}\text { perforations with smooth, } \\
\text { rounded margins about } 1 \\
\text { mm or larger in size with } \\
\text { the appearance of a } \\
\text { channel, but the internal } \\
\text { aspect is rarely visible. } \\
\text { Do not score if they at } \\
\text { the base of an erosion. }\end{array}$ & \\
\hline
\end{tabular}

\section{Statistical Analysis}

The Man-Whitney U test was chosen for two reasons. The test is non-parametric and does not assume a normal distribution. Nonparametric statistics make no assumptions about the probability distributions of the variables assessed. The difference between parametric models and non-parametric models is that the former has a fixed number of parameters, while the latter grows the number of parameters with the amount of training data. The Man-Whitney U Test is also flexible and functions nearly as well a t-test if the data happen to be normally distributed. Additionally, the test is not based on occurrences, like a Fischer's Exact Test, and allows for entering decimal numbers.

The individual burial means described in the following chapter's charts were obtained by calculating the average of the left of right side scores for the desired enthesis. Individual burial 
means were then placed within one of three age categories (15-30, 31-44, 45-55+) within their appropriate sex category (when sex assessment was possible). Man-Whitney U-Test results used individual burial means. Due to preservation, both the infraspinatus and supraspinatus had sample sizes that did not meet the Man-Whitney U-Test minimum sample size threshold. Therefore, this test was not conducted on these entheses.

Z-scores were also used to assess variance from the individual burial mean for fifteen mound burials. The scores indicate how many standard deviations an element is from the mean. A z-score can be calculated from the following formula: $z=(X-\mu) / \sigma . Z$ is the resulting $z$-score, $\mathrm{X}$ is the sample mean, $\mu$ is the population mean, and $\sigma$ is the standard deviation. In this study, $\mathrm{X}$ is the mean score of one mound burial. $\mu$ is the mean of the appropriate age and sex cohort (young, middle-aged, old age, male, or female), and $\sigma$ is the standard deviation for the appropriate age and sex cohort. For example, if a mound burial was a middle aged male, then the population mean and population standard deviation for middle aged males would be used in this particular z-score calculation. Z-scores are easily interpretable. The score simply indicates how many standard deviations above or below the mean a particular "case” is. Positive scores indicate variance above the mean. Negative scores indicate variance below the mean. If the number of elements in the set is large, about $68 \%$ of the elements have a z-score between -1 and 1; about 95\% have a z-score between -2 and 2; and about 99\% have a z-score between -3 and 3. A z-score typically begins to approach statistical significance as it approaches 2 or -2 since only $5 \%$ of the total variance of the population lies outside of 2 standard deviations from the mean.

\section{Final Score Calculation Example}

Burial 9 serves as an example because it had very good preservation and allowed for near complete data collection. Table 4.2 shows the complete data collection for Burial 9. NP indicates 
not present and that the enthesis was too incomplete to score and no data was collected.A mean was calculated for each row of data (Table 4.3). Then, left and right side means were averaged together resulting in the means, which were used in all Man-Whitney U-Test calculations to produce the tables and figures in Chapter Five; however, Figures 5.10 and 5.11 persevered the original left and right averages in Table 4.3.

Table 2

Complete Data for Burial 9.

\begin{tabular}{|c|c|c|c|c|c|c|}
\hline & $\begin{array}{c}\text { BF } \\
\text { Z1 }\end{array}$ & $\begin{array}{c}\text { ER } \\
\text { Z1 }\end{array}$ & $\begin{array}{c}\text { BF } \\
\text { Z2 }\end{array}$ & $\begin{array}{c}\text { ER } \\
\text { Z2 }\end{array}$ & FPO & MPO \\
\hline $\begin{array}{c}\text { Biceps Brachii Long Head Origin } \\
\text { (Supraglenoid Tubercle) Left }\end{array}$ & 0 & 0 & 0 & 0 & 0 & 0 \\
\hline $\begin{array}{c}\text { Biceps Brachii Long Head Origin } \\
\text { (Supraglenoid Tubercle) Right }\end{array}$ & 1 & 0 & 0 & 0 & 0 & 0 \\
\hline $\begin{array}{c}\text { Biceps Brachii Insertion (Radial Tuberosity) } \\
\text { Left }\end{array}$ & 0 & 0 & 1 & 0 & 1 & 0 \\
\hline $\begin{array}{c}\text { Biceps Brachii Insertion (Radial Tuberosity) } \\
\text { Right }\end{array}$ & 0 & 0 & 1 & 0 & 1 & 0 \\
\hline $\begin{array}{c}\text { Triceps Brachii Long Head Origin } \\
\text { (Infraglenoid Tubercle) Left }\end{array}$ & 0 & 0 & 0 & 0 & 0 & 0 \\
\hline $\begin{array}{c}\text { Triceps Brachii Long Head Origin } \\
\text { (Infraglenoid Tubercle) Right }\end{array}$ & 0 & 0 & 0 & 0 & 0 & 0 \\
\hline $\begin{array}{c}\text { Triceps Brachii Lateral/Medial Origin } \\
\text { (Radial Sulcus) Left }\end{array}$ & 0 & 0 & 0 & 0 & 0 & 0 \\
\hline $\begin{array}{c}\text { Triceps Brachii Lateral/Medial Origin } \\
\text { (Radial Sulcus) Right }\end{array}$ & 0 & 0 & 0 & 0 & 0 & 0 \\
\hline $\begin{array}{c}\text { Triceps Brachii Insertion (Olecrannon } \\
\text { Process) Left }\end{array}$ & 1 & 0 & 1 & 0 & 0 & 1 \\
\hline $\begin{array}{c}\text { Triceps Brachii Insertion (Olecrannon } \\
\text { Process) Right }\end{array}$ & 1 & 0 & 1 & 0 & 1 & 0 \\
\hline $\begin{array}{c}\text { (Table Continues) } \\
\text { (n) }\end{array}$ & & & & & 0 & \\
\hline
\end{tabular}




\begin{tabular}{|c|c|c|c|c|c|c|}
\hline & $\begin{array}{l}\mathrm{BF} \\
\mathrm{Z} 1\end{array}$ & $\begin{array}{l}\mathrm{ER} \\
\mathrm{Z} 1\end{array}$ & $\begin{array}{l}\mathrm{BF} \\
\mathrm{Z} 2\end{array}$ & $\begin{array}{l}\mathrm{ER} \\
\mathrm{Z2}\end{array}$ & FPO & MPO \\
\hline $\begin{array}{c}\text { Infraspinatus Origin (Infraspinatus Fossa) } \\
\text { Left }\end{array}$ & NP & NP & NP & NP & NP & NP \\
\hline $\begin{array}{c}\text { Infraspinatus Origin (Infraspinatus Fossa) } \\
\text { Right } \\
\end{array}$ & NP & NP & NP & NP & NP & NP \\
\hline $\begin{array}{c}\text { Infraspinatus Insertion (Middle Greater } \\
\text { Tubercle) Left }\end{array}$ & 0 & 0 & 0 & 0 & 1 & 1 \\
\hline $\begin{array}{c}\text { Infraspinatus Insertion (Middle Greater } \\
\text { Tubercle) Right }\end{array}$ & 0 & 0 & 0 & 0 & 1 & 2 \\
\hline $\begin{array}{c}\text { Supraspinatus Origin (Supraspinatus Fossa) } \\
\text { Left } \\
\end{array}$ & NP & NP & NP & $\mathrm{NP}$ & $\mathrm{NP}$ & NP \\
\hline $\begin{array}{c}\text { Supraspinatus Origin (Supraspinatus Fossa) } \\
\text { Right }\end{array}$ & NP & NP & NP & NP & NP & NP \\
\hline $\begin{array}{c}\text { Supraspinatus Insertion (Superior Greater } \\
\text { Tubercle) Left } \\
\end{array}$ & 0 & 0 & 1 & 0 & 0 & 0 \\
\hline $\begin{array}{c}\text { Supraspinatus Insertion (Superior Greater } \\
\text { Tubercle) Right }\end{array}$ & 0 & 0 & 0 & 0 & 0 & 0 \\
\hline $\begin{array}{c}\text { Deltoideus Anterior Origin (Inferiolateral } \\
\text { Thrid of Clavicle) Left }\end{array}$ & 0 & 1 & 0 & 0 & 1 & 0 \\
\hline $\begin{array}{c}\text { Deltoideus Anterior Origin (Inferiolateral } \\
\text { Third of Clavicle) Right } \\
\end{array}$ & 0 & 1 & 0 & 0 & 1 & 0 \\
\hline $\begin{array}{c}\text { Deltoideus Anterior Insertion (Deltoid } \\
\text { Tuberosity) Left }\end{array}$ & 0 & 0 & 0 & 0 & 0 & 0 \\
\hline $\begin{array}{c}\text { Deltoideus Anterior Insertion (Deltoid } \\
\text { Tuberosity) Right }\end{array}$ & 0 & 0 & 0 & 0 & 0 & 0 \\
\hline $\begin{array}{c}\text { Deltoideus Lateral Origin (Superior } \\
\text { Acrominon Process) Left } \\
\end{array}$ & NP & NP & NP & NP & NP & NP \\
\hline $\begin{array}{c}\text { Deltoideus Lateral Origin (Superior } \\
\text { Acrominon Process) Right } \\
\end{array}$ & $\mathrm{NP}$ & NP & NP & $\mathrm{NP}$ & $\mathrm{NP}$ & NP \\
\hline $\begin{array}{c}\text { Deltoideus Lateral Insertion (Deltoid } \\
\text { Tuberosity) Left }\end{array}$ & 0 & 0 & 0 & 0 & 0 & 0 \\
\hline $\begin{array}{c}\text { Deltoideus Lateral Insertion (Deltoid } \\
\text { Tuberosity) Right }\end{array}$ & 0 & 0 & 0 & 0 & 0 & 0 \\
\hline $\begin{array}{c}\text { Deltoideus Posterior Origin (Inferior } \\
\text { Boarder of Scapular Spine) Left }\end{array}$ & NP & NP & NP & NP & NP & NP \\
\hline $\begin{array}{c}\text { Deltoideus Posterior Origin (Inferior } \\
\text { Boarder of Scapular Spine) Right }\end{array}$ & NP & NP & NP & NP & NP & NP \\
\hline $\begin{array}{c}\text { Deltoideus Posterior Insertion (Deltoid } \\
\text { Tuberosity) Left } \\
\end{array}$ & 0 & 0 & 0 & 0 & 0 & 0 \\
\hline $\begin{array}{c}\text { Deltoideus Posterior Insertion (Deltoid } \\
\text { Tuberosity) Right }\end{array}$ & 0 & 0 & 0 & 0 & 0 & 0 \\
\hline
\end{tabular}




\begin{tabular}{|c|c|c|c|c|c|c|}
\hline & $\begin{array}{c}\text { BF } \\
\text { Z1 }\end{array}$ & $\begin{array}{c}\text { ER } \\
\text { Z1 }\end{array}$ & $\begin{array}{c}\text { BF } \\
\text { Z2 }\end{array}$ & $\begin{array}{c}\text { ER } \\
\text { Z2 }\end{array}$ & FPO & MPO \\
\hline $\begin{array}{c}\text { Pectoralis Major Origin (Medioinferior } \\
\text { Medial Third of Clavicle) Left }\end{array}$ & 1 & 0 & 0 & 0 & 0 & 0 \\
\hline $\begin{array}{c}\text { Pectoralis Major Origin (Medioinferior } \\
\text { Medial Third of Clavicle) Right }\end{array}$ & 1 & 0 & 1 & 0 & 0 & 0 \\
\hline $\begin{array}{c}\text { Pectoralis Major Insertion (Lateral Lip of } \\
\text { Bicipital Groove) Left }\end{array}$ & 1 & 0 & 1 & 0 & 0 & 0 \\
\hline $\begin{array}{c}\text { Pectoralis Major Insertion (Lateral Lip of } \\
\text { Bicipital Groove) Right }\end{array}$ & 1 & 0 & 1 & 0 & 0 & 1 \\
\hline
\end{tabular}

Table 3

Final Mean Scores for Burial 9

\begin{tabular}{|l|c|}
\hline Biceps Average (Left) & 0 \\
\hline Biceps Average (Right) & 0.16666667 \\
\hline Triceps Average (Left) & 0.1111111 \\
\hline Triceps Average (Right) & 0.1111111 \\
\hline Infraspinatus Average (Left) & 0.5 \\
\hline Infraspinatus Average (Right) & 0.5 \\
\hline Supraspinatus Average (Left) & 0.33333333 \\
\hline Supraspinatus Average (Right) & 0.5 \\
\hline Deltoideus Average (Left) & 0.125 \\
\hline Deltoideus Average (Right) & 0.08333333 \\
\hline Pectoralis Average (Left) & 0.08333333 \\
\hline Pectoralis Average (Right) & 0.16666667 \\
\hline
\end{tabular}

\section{Aging and Sexing Methodology}

Sexing and aging information primarily came from a data base on file at the McClung Museum of Natural History and Culture (1968-1989 inventory [Collections Improvement Grant, BNS-8606641 Smith]). In some cases, the spreadsheet did not contain sex or age information. In 
those cases, sex was determined using non-metric variables on the pelvis and skull (e.g. mastoid processes, supraorbital tori, supraorbital margin, greater sciatic notch, and subpubic angle) (Bass 2005, Phenice 1969). A variety of non-metric traits and recent refinements of pelvis and skull sex indicators (Buikstra and Ubelaker 1994, Suchey-Brooks 1990) were additionally employed to assign a sex to questionable (e.g. probable male, probable female) or previously unsexable individuals. Age was primarily determined using a combination of Suchey-Brook’s (1990) pubic symphysis sequence and Lovejoy et al's (1985) auricular surface sequence in cases were pubic symphyses were not available. Several individuals $(\mathrm{N}=5)$ were not able to be sexed or to be aged accurately enough with the above methods to fit into the previously defined age and sex categories. 


\section{CHAPTER V: RESULTS}

The following charts and data are the results of the various Man-Whitney U Tests and general trends based on the averages of entheseal scores. Table 4 displays the average of the combined left and right side scores for each enthesis by sex. The numbers were obtained from methods previously defined in Chapter IV using the following formula: $\bar{x}$ (left enthesis) $+\bar{x}$ (right enthesis) / 2. Figure 5 graphically presents the differences between the sexes for each enthesis. If a male average score is higher than the female, the difference is graphed as a positive number (i.e. above the zero line). If the difference was higher in females, the score was graphed as a negative number (i.e. below the zero line).

Table 4

Average Entheseal Scores by Sex.

\begin{tabular}{|l|r|}
\hline Biceps Male Average & 0.1539 \\
\hline Biceps Female Average & 0.0933 \\
\hline Triceps Male Average & 0.1753 \\
\hline Triceps Female Average & 0.0810 \\
\hline Infraspinatus Male Average & 0.0833 \\
\hline Infraspinatus Female Average & 0.2843 \\
\hline Supraspinatus Male Average & 0.0555 \\
\hline Supraspinatus Female Average & 0.0516 \\
\hline Deltoideus Male Average & 0.2140 \\
\hline Deltoideus Female Average & 0.1934 \\
\hline Pectoralis Male Average & 0.2453 \\
\hline Pectoralis Female Average & 0.2513 \\
\hline
\end{tabular}




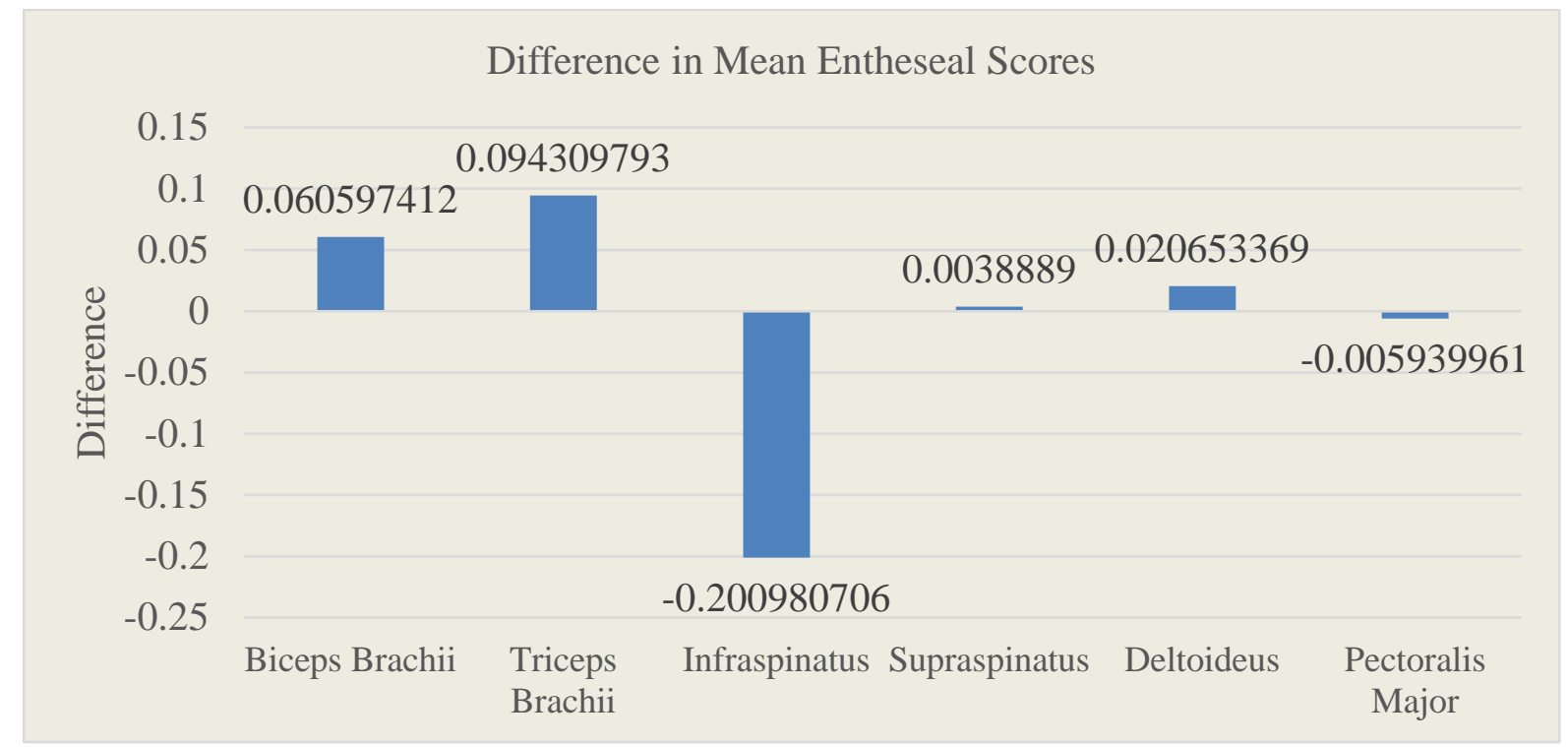

Figure 5. Differences in mean entheseal scores. Positive values indicate higher male mean score. Negative values indicate higher female mean score.

The results in Table 5-9 are based on means from Table 1. The tables note areas of significance based on the differences of Figure 5. The table depicts areas in which the difference between males and females are significantly different across their lifetime. The test shows only one area of significance (triceps brachii), which indicates and highlights possible differences across a lifetime of usage between sex groups. 
Table 5

Significance of Male and Female Differences across All Age Groups.

\begin{tabular}{|l|c|c|c|c|}
\hline & Z Score & U & P Value & Sample Size \\
\hline Biceps Brachii & -2.76288 & 1740.5 & $.0057^{*}$ & 146 \\
\hline Triceps Brachii & -3.19573 & 1902.5 & $.0013^{*}$ & 149 \\
\hline Infraspinatus & 0.85739 & 45.5 & .3897 & 24 \\
\hline Supraspinatus & -0.33243 & 130 & .7414 & 34 \\
\hline Deltoideus & -1.8291 & 2733.5 & .0672 & 162 \\
\hline Pectoralis Major & -0.11192 & 2561.5 & .9124 & 145 \\
\hline
\end{tabular}

Note: $\mathrm{P}<.05$ are considered significant. Asterisk indicates statistical significance.

Tables 6-9 shows the results of the Man-Whitney U-Test, which compared the entheseal scores of biceps brachii, triceps brachii, pectoralis major, and deltoideus for each age group. Infraspinatus and supraspinatus were not included in this testing because their sample size was very small and did not meet the minimum requirements for the Man-Whitney U-Test. Each age category compared males and females of that age category. The tests show how entheseal scores varied between age groups and provides the basis for insight concerning how different age and sex group utilized muscle groups.

Table 6 shows the results of the Man-Whitney U-Test, which compared the entheseal scores of biceps brachii for each age group. Each age category compared males and females of that age category. The test returned no values of statistical significance, which indicates that pectoralis major usage did not vary at statistical significance levels within any age group. 
Table 6

Man-Whitney U-Test Sex and Age Group Comparison for Biceps Brachii.

\begin{tabular}{|c|c|c|c|c|}
\hline & Z- Score & U & P Value & Sample Size \\
\hline Male vs Female 15-30 & -1.5284 & 202.5 & 0.1260 & 48 \\
\hline Male vs Female 31-44 & -1.3229 & 283.5 & 0.1864 & 54 \\
\hline Male vs Female 45-55+ & 1.4445 & 109.5 & 0.1498 & 38 \\
\hline
\end{tabular}

Note: Asterisk indicate statistical significance. $\mathrm{P}<.05$ are considered significant.

Table 7 shows the results of the Man-Whitney U-Test, which compared the entheseal scores of triceps brachii for each age group. Each age category compared males and females of that age category. The test returned statistically significant values for the 31-44 and 45-55+ age groups indicating that females in those age groups utilized their triceps at differing intensity levels. This finding correlates with Table 5, which found that the triceps brachii was one enthesis with a statistical significance across a lifetime. The results indicate that differential usage begins and is most significant within the 31-44 group.

Table 7

Man-Whitney U-Test Sex and Age Group Comparison for Triceps Brachii.

\begin{tabular}{|c|c|c|c|c|}
\hline & Z Score & U & P Value & Sample Size \\
\hline Male vs. Female 15-30 & -1.2574 & 236 & 0.2076 & 50 \\
\hline Male vs. Female 31-44 & -2.2036 & 188.5 & $0.0278^{*}$ & 49 \\
\hline Male vs. Female 45-55+ & 2.1345 & 115.5 & $0.0331^{*}$ & 42 \\
\hline
\end{tabular}

Note: Asterisk indicate statistical significance. $\mathrm{P}<.05$ are considered significant. 
Table 8 shows the results of the Man-Whitney U-Test, which compared the entheseal scores of pectoralis major for each age group. Each age category compared males and females of that age category. The test returned no values of statistical significance, which indicates that pectoralis major usage did not vary at statistically significance levels within any age group.

Table 8

Man-Whitney U-Test Sex and Age Group Comparison for Pectoralis Major.

\begin{tabular}{|c|c|c|c|c|}
\hline & Z Score & U & P Value & Sample Size \\
\hline Male vs. Female 15-30 & 0.80781 & 268.5 & 0.4179 & 50 \\
\hline Male vs. Female 31-44 & -0.28284 & 279.5 & 0.7794 & 49 \\
\hline Male vs. Female 45-55+ & 0.55116 & 150 & 0.5823 & 39 \\
\hline
\end{tabular}

Note: Asterisk indicate statistical significance. $\mathrm{P}<.05$ are considered significant.

Table 9 shows the results of the Man-Whitney U-Test, which compared the entheseal scores of deltoideus for each age group. Each age category compared males and females of that age category. The test returned statistically significant values for the 15-30 age group indicating that males in that age group utilized the deltoideus at differing intensity levels within that age group. This finding also correlates with Table 5, which shows that the difference in lifetime usage reached levels of near statistical significance $(\mathrm{P}=.0672)$. 
Table 9

Man-Whitney U-Test Sex and Age Group Comparison for Deltoideus.

\begin{tabular}{|c|c|c|c|c|}
\hline & Z Score & U & P Value & Sample Size \\
\hline Male vs. Female 15-30 & -2.76365 & 211 & $0.0057^{*}$ & 55 \\
\hline Male vs. Female 31-44 & -1.55456 & 260.5 & 0.1211 & 53 \\
\hline Male vs. Female 45-55+ & -0.09701 & 258.5 & 0.9203 & 48 \\
\hline
\end{tabular}

Note: Asterisk indicate statistical significance. $\mathrm{P}<.05$ are considered significant.

Figures 6 and 7 represent the general trends between the sexes at each muscle with the previously defined age groups. The scores were obtained through the previously described averaging methodology. The figures graphically depict the means used in the Man-Whitney UTests results in Tables 6-9. The figures show how entheseal scores varied between age groups within males (Figure 6) and females (Figure 7). In Figure 6, the large peak of infraspinatus and supraspinatus is an artifact of sample size. The previous age group (15-30) had no scorable supraspinatus or infraspinatus entheses. The 31-44 and 45-55+ age groups also had very few scorable entheses and did not meet the minimum threshold for the Man-Whitney U-Test. Thus, assessment of the statistical significance of the middle age was not possible. 


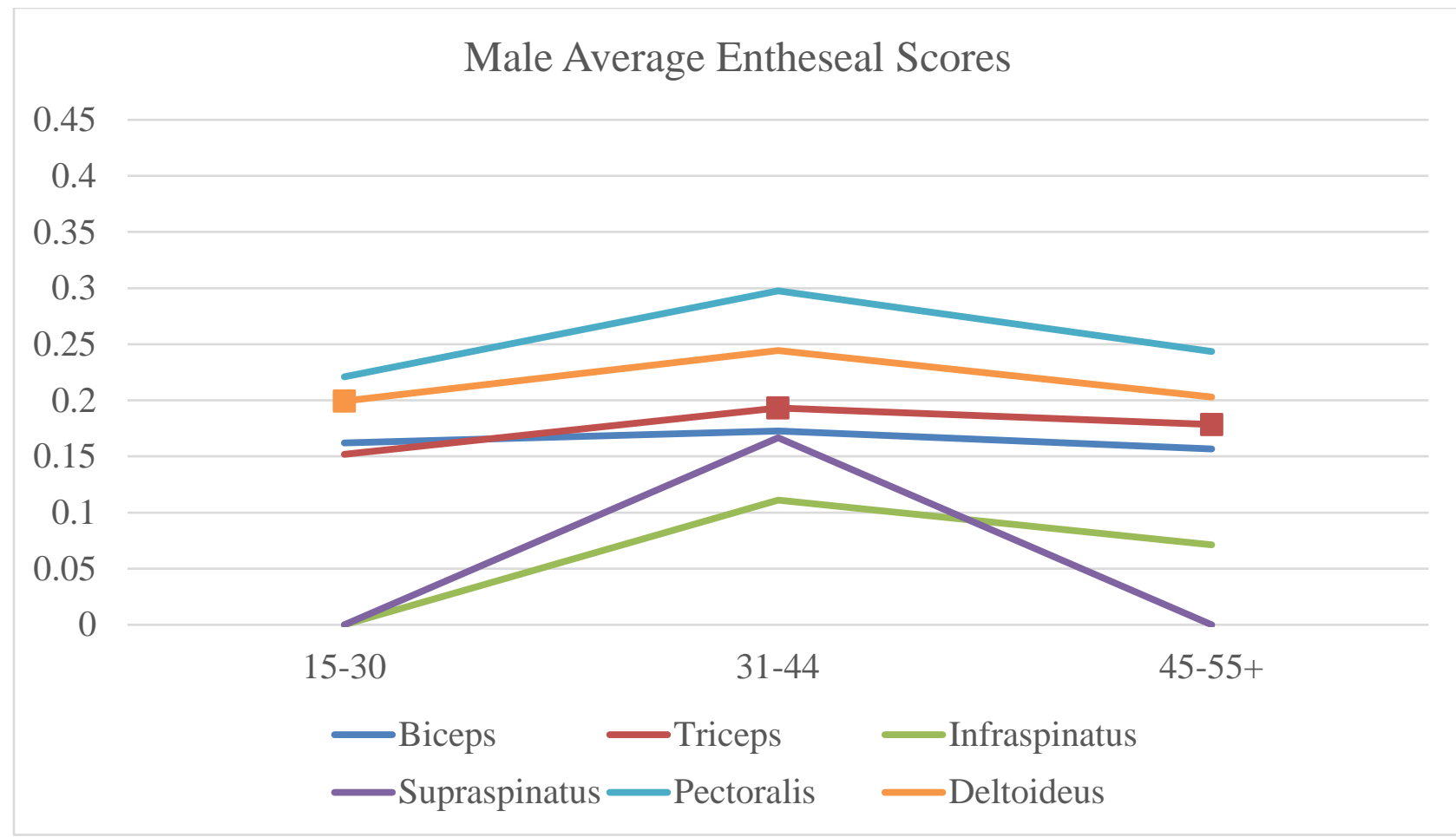

Figure 6. Male average entheseal scores. Squares indicate statistically significant differences between male and female scores based on the U-test in Tables 6-9. 


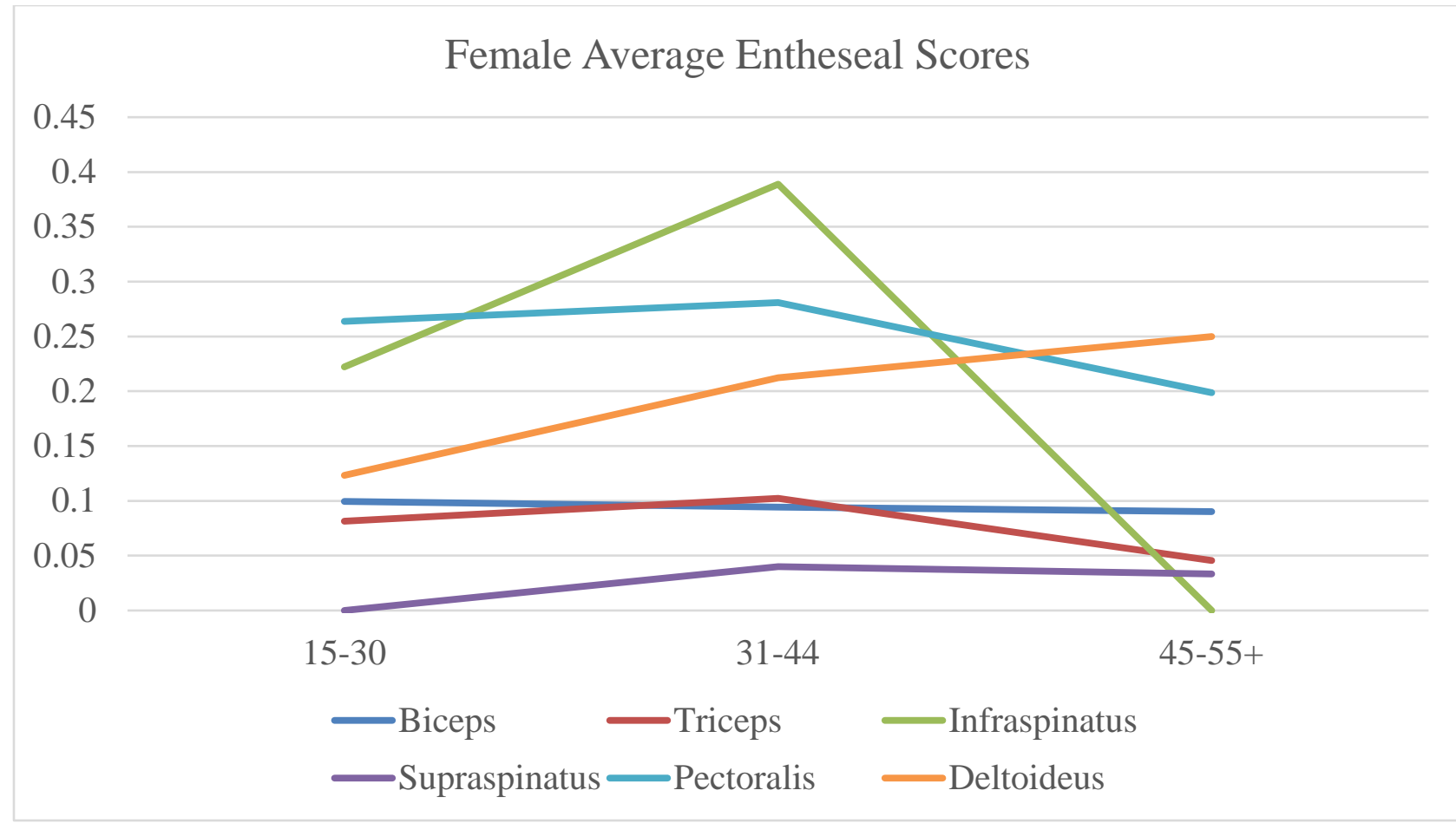

Figure 7. Female average entheseal scores. No areas of statisically significant differences appear between females and males despite occasional higher absolute values.

Figures 8-13 represent the inter-individual variance between males and females at each age group. Each black line on the chart shows the mean entheseal score for left and right side of the given enthesis for an individual burial within that age and sex group. The two colored lines represent the combined left and right side mean entheseal score for all individuals within the age and sex group at the given enthesis. The graphs display how individual trends correlate to overall trends within age and sex groupings. Special attention should be placed on the degree to which lines cluster around their associated sex group mean as well as to those individuals, which deviate from their sex and age mean line and groupings. 
Figure 8 shows more clustering at deltoideus and pectoralis and a lesser degree of clustering takes at the biceps and triceps, which are notated by triangles. Triceps in particular has three individuals that display much higher scores than the male mean entheseal score for the young age group.

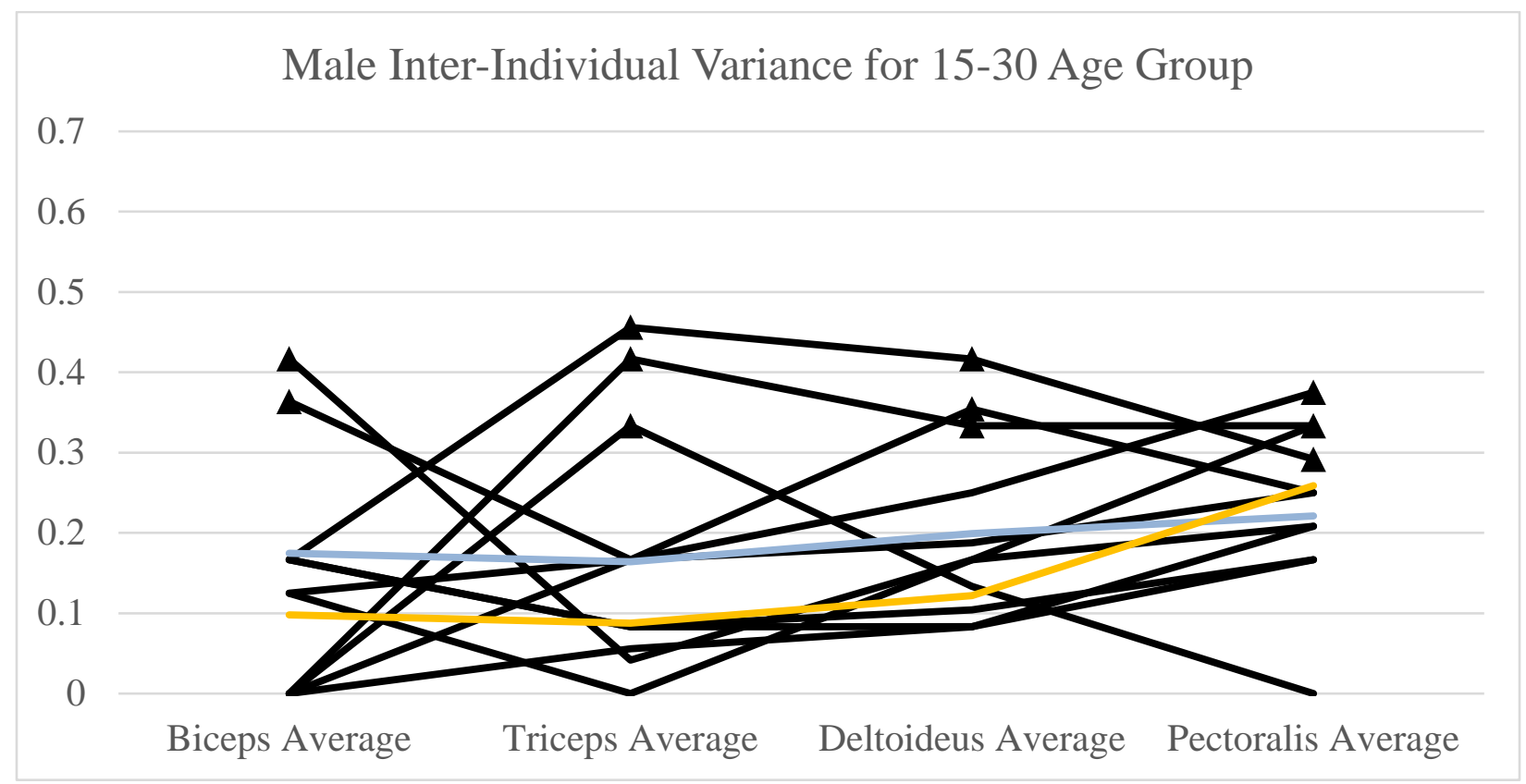

Figure 8. Male inter-individual variance for 15-30 age group. Black lines are individual burial entheseal mean scores. The blue colored line is overall male mean entheseal score. The orange colored line is overall female mean entheseal score.

Figure 9 shows a different pattern to previous figure. Female scores for the younger age group display much tighter clustering not only to each other but also to the overall female mean 
entheseal score. Only a few individuals display significant spiking in any of the group, which are notated by the triangles.

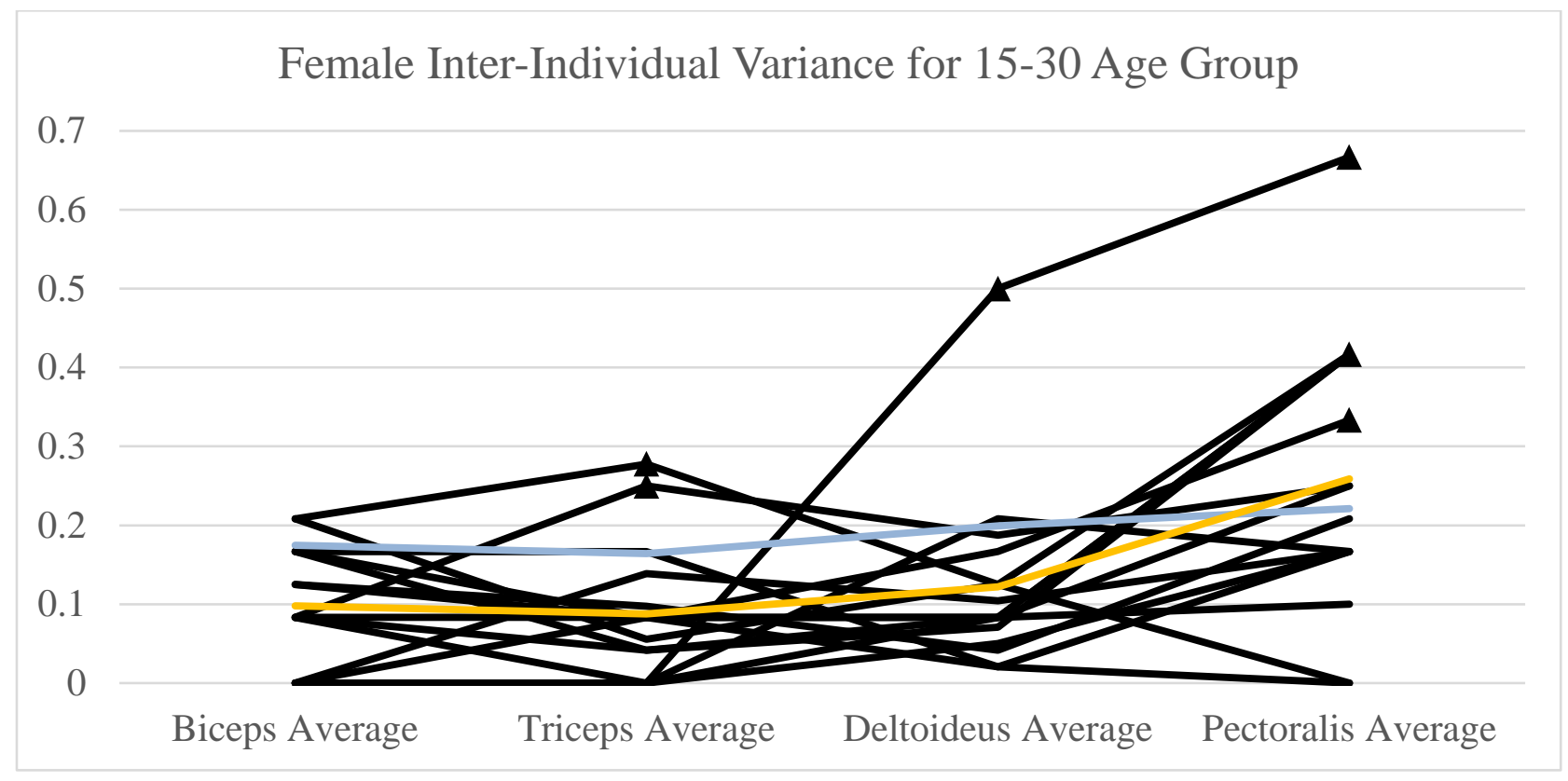

Figure 9. Female inter-individual variance for 15-30 age group. Black lines are individual burial entheseal mean scores. The blue colored line is overall male mean entheseal score. The orange colored line is overall female mean entheseal score.

Figure 10 appears to follow the overall male trend shown in Figure 8. As in the previous male age group, there is less clustering at the male mean; however, male scores do tend to cluster with one another. Six males also fall below the overall male mean entheseal score at all or nearly all entheses (denoted by green lines) and are not similar to the female pattern. 


\section{Male Inter-Individual Variation for 31-44 Age Group}

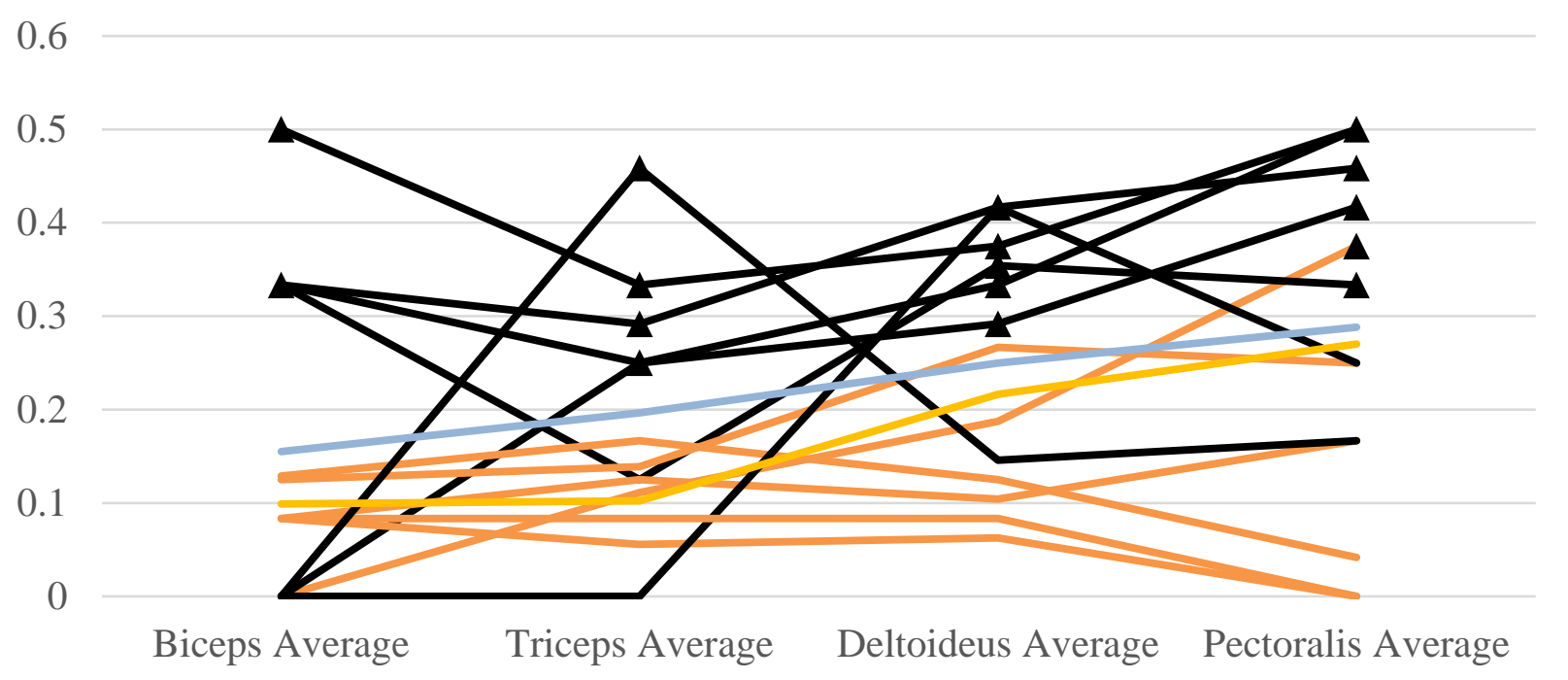

Figure 10. Male inter-individual variation for 31-44 age group. Blac0k lines are individual burial entheseal mean scores. The blue colored line is overall male mean entheseal score. The orange colored line is overall female mean entheseal score.

Figure 11 shows a very similar pattern the previous Figure 9. As in the previous female age group, there is a greater degree of clustering around the female mean relative to the previous figure. This may indicate that a greater number of females were engaged in a similar set of activities at this age group than the previous. A few individuals have scores higher than the over female mean (denoted by triangles). Many fall near or below overall female mean entheseal score. 


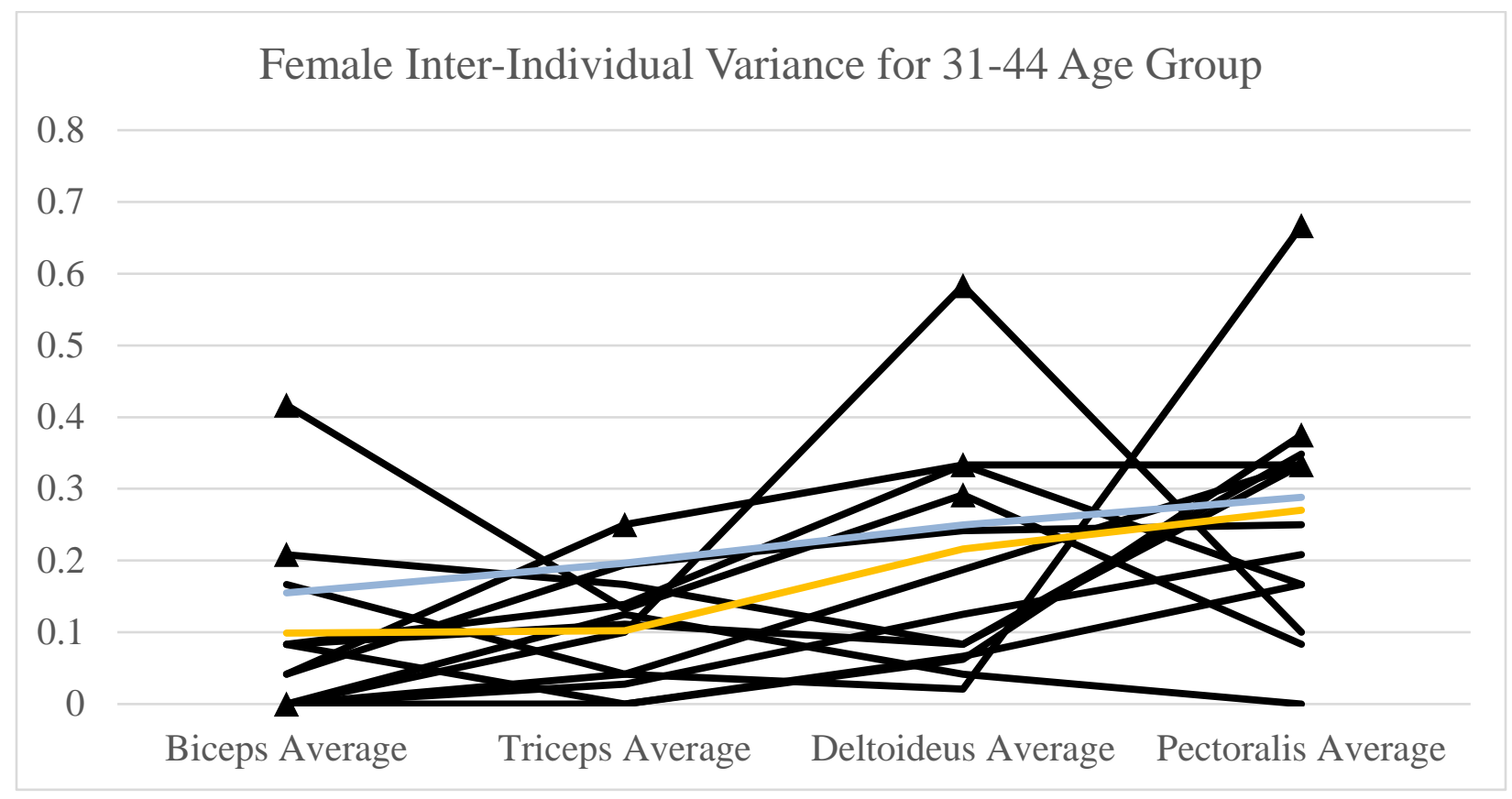

Figure 11. Female inter-individual variance for 31-44 age group. Black lines are individual burial entheseal mean scores. The blue colored line is overall male mean entheseal score. The orange colored line is overall female mean entheseal score.

Figure 12 shows a pattern that is distinct from the previous male patterns (Figures 8 and 10). Unlike the previous two age groups, more clustering occurs at or around the overall male mean entheseal score. Fewer scores spike above the overall male mean score (denoted by triangles) relative to the first figure and two male individuals more closely resemble the female than male pattern (red lines). 


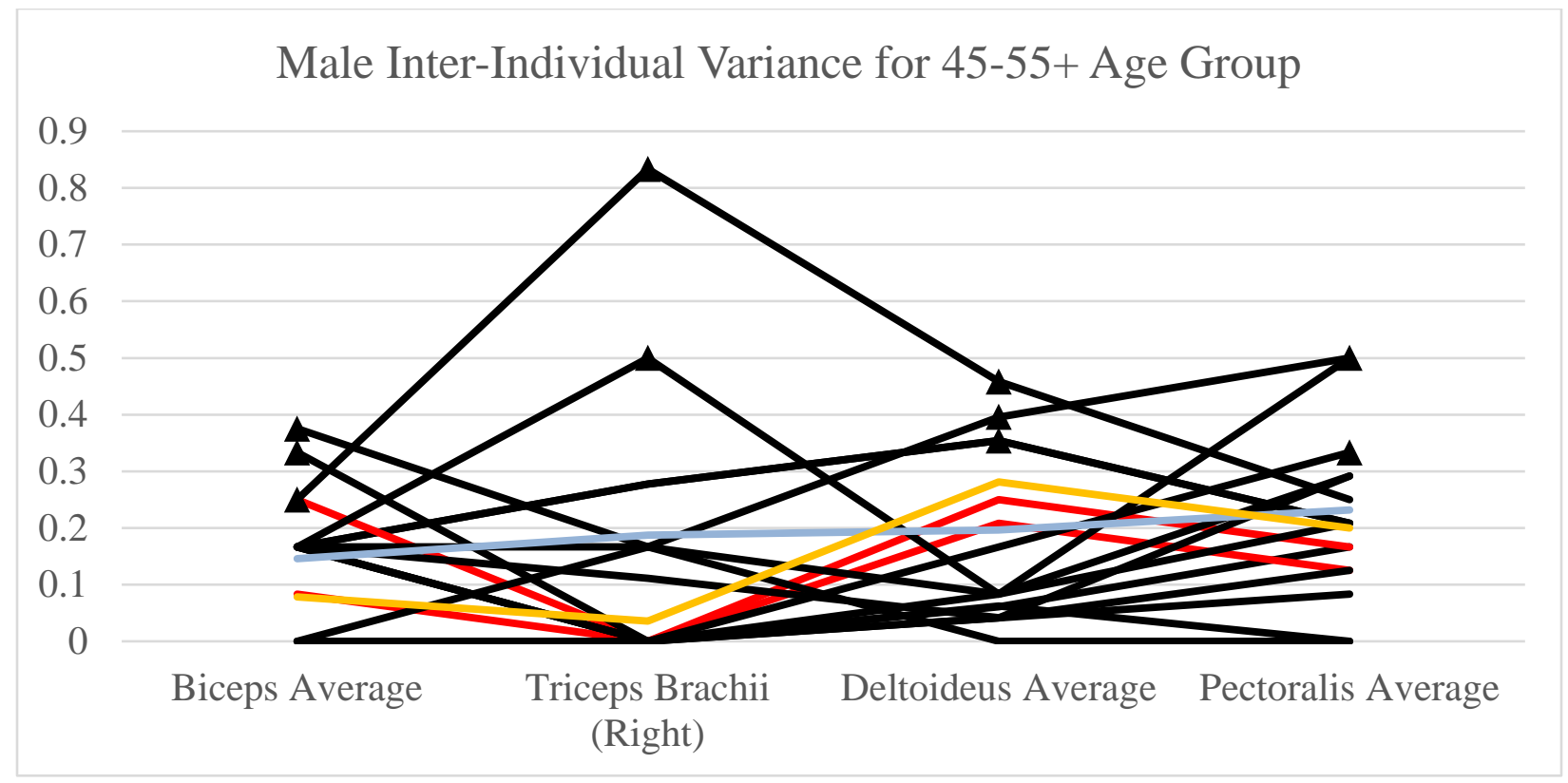

Figure 12. Male inter-individual variance for 45-55+ age group. Black lines are individual burial entheseal mean scores. The blue colored line is overall male mean entheseal score. The orange colored line is overall female mean entheseal score.

Figure 13 shows a change in pattern relative to the two previous female age groups (Figures 9 and 11). Unlike the previous age group, individual age scores very greatly from the overall female mean entheseal score. This could be a product of small sample size as well since the sample size for females of this age group is small $(\mathrm{N}=7)$. Perhaps more definitive clustering would occur with a great sample size. 


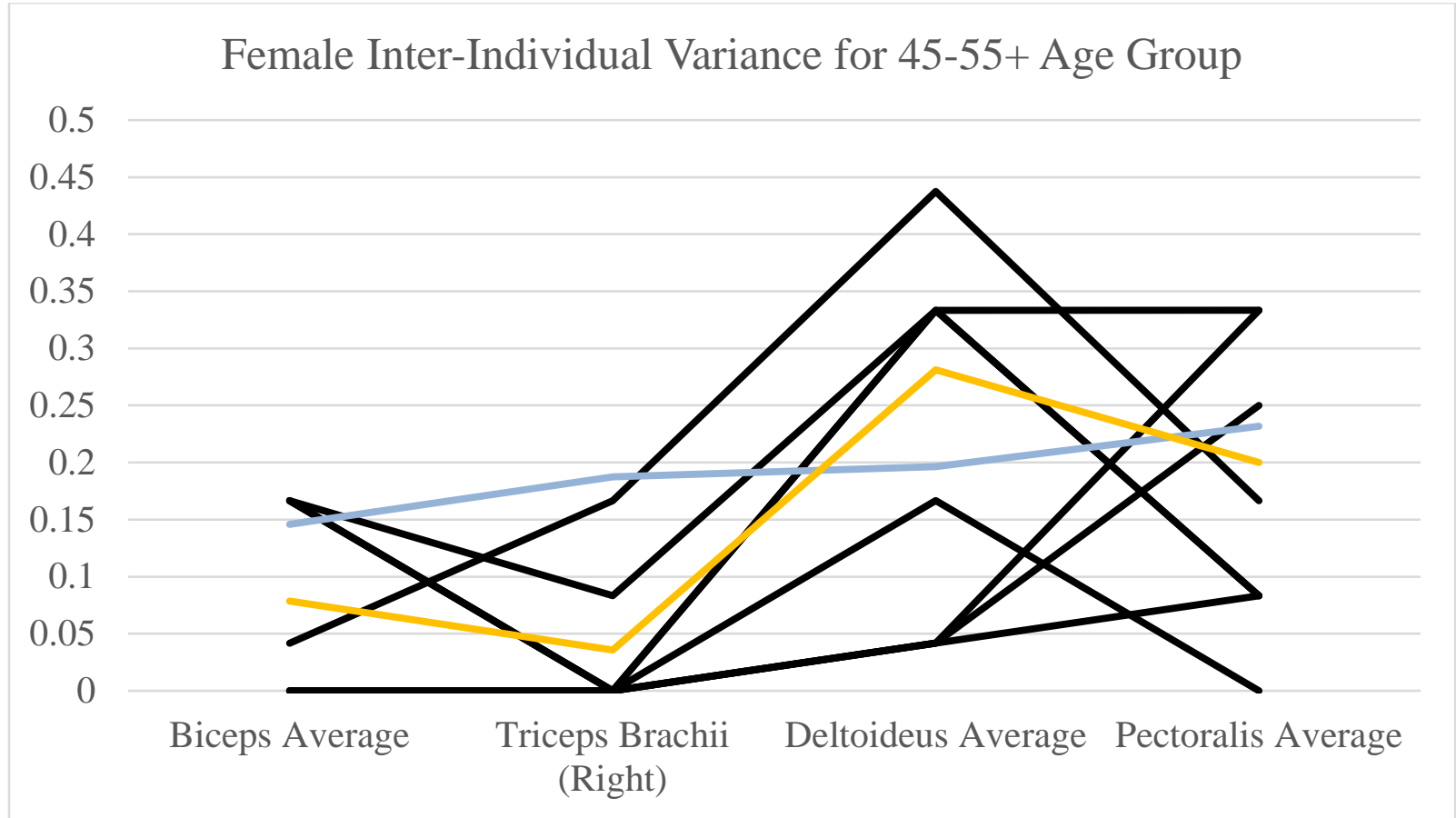

Figure 13. Female inter-individual variance for $45-55+$ age group. Black lines are individual burial entheseal mean scores. The blue colored line is overall male mean entheseal score. The orange colored line is overall female mean entheseal score.

Figures 14 and 15 show the bilateral average scores for each entheses within each age group. Mean scores were calculated for each both sides at each entheses within the age group following the above described method (v. Ch.4). The purpose of the figures was to explore any labor patterns involving unilateral preference; however, the Man-Whitney U-Tests did not produce any statistically significant results. 


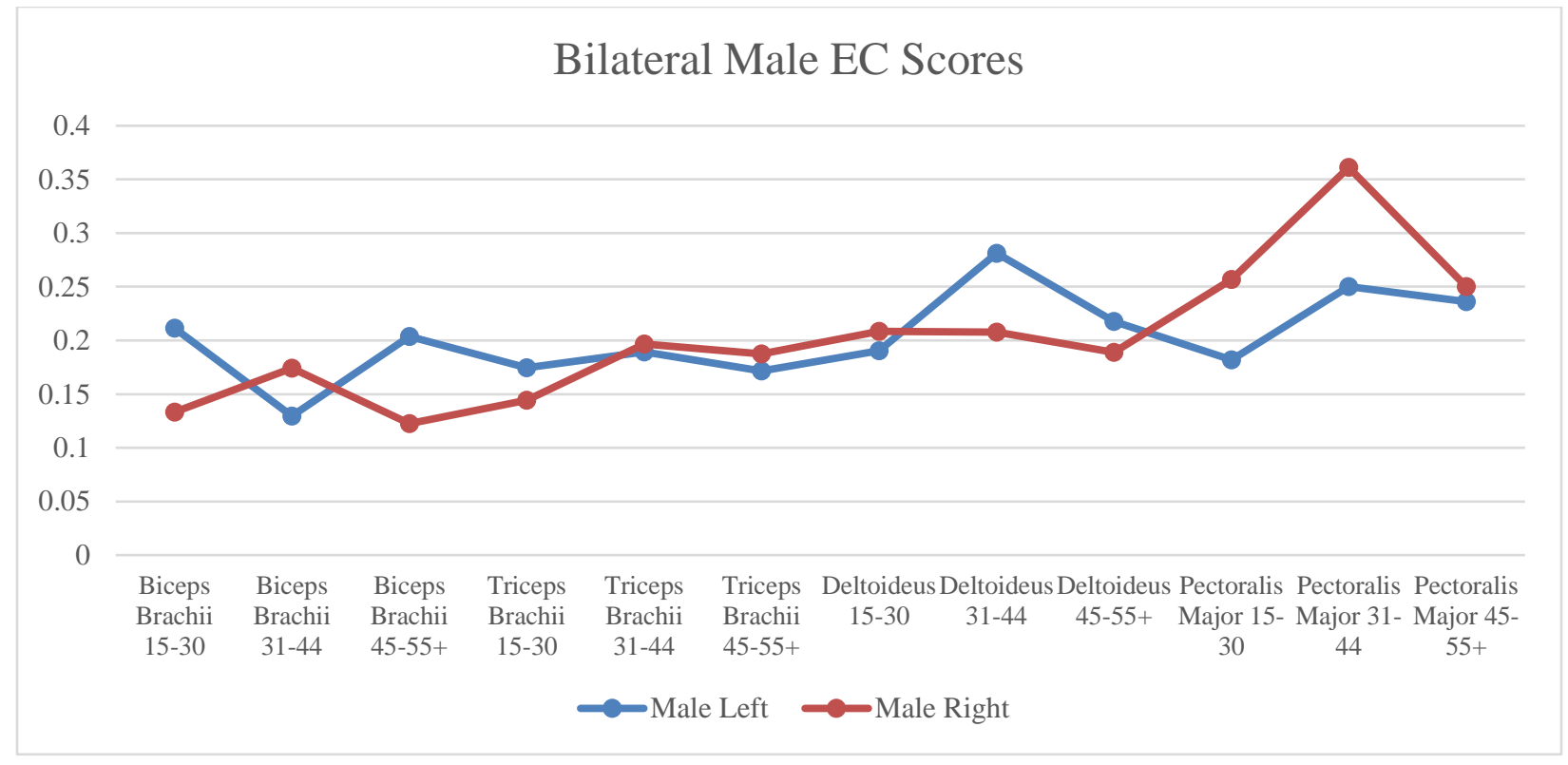

Figure 14. Bilateral male EC scores. Left and right side entheseal mean scores by enthesis.

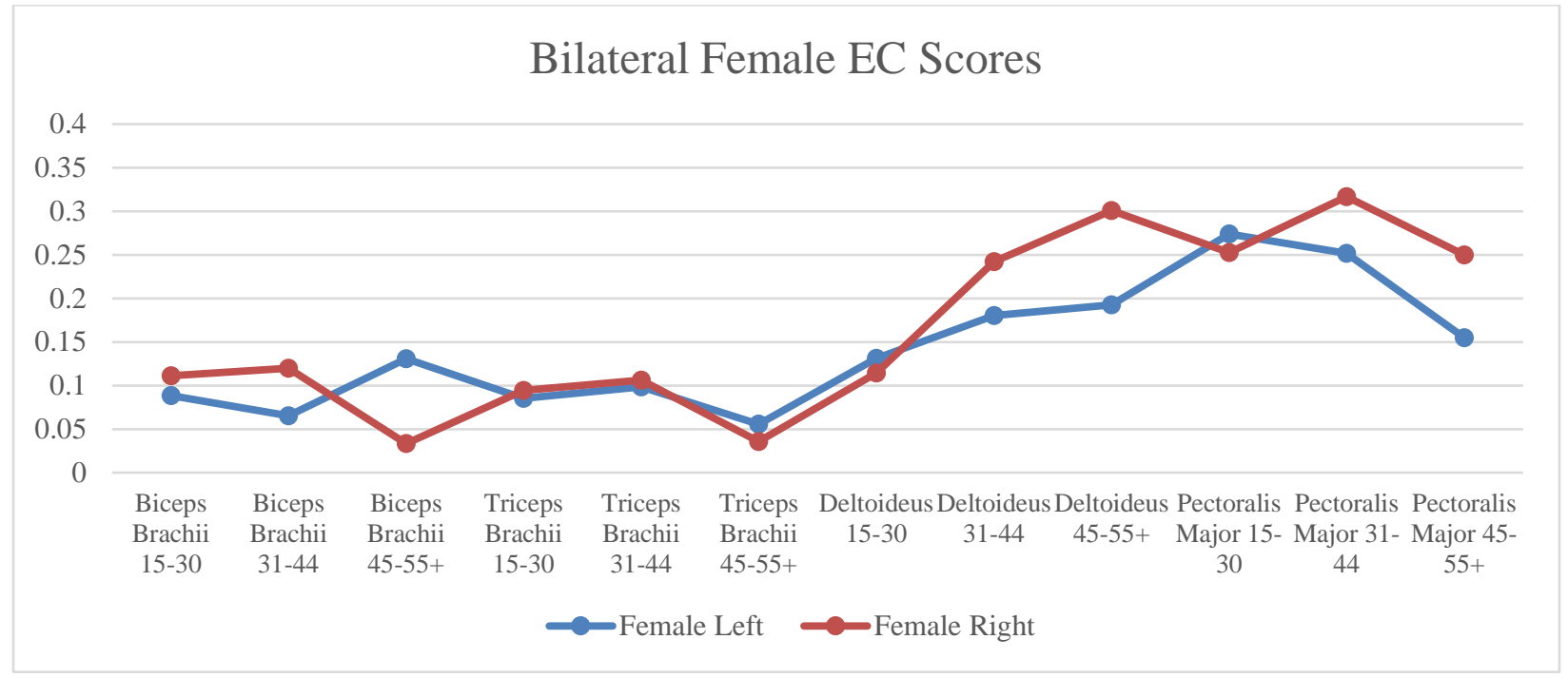

Figure 15. Bilateral female EC Scores. Left and right side entheseal mean scores by enthesis.

Table 5.7 shows the results of the Z-score tests of the mound burials compared to the village burials, which would indicate if any statistically significant variance occurred between 
those buried in the mound and those buried in the village. Z-scores were chosen because of the small sample size of mound burials. The burials are organized by age and sex groups. Burials 136, 137, and 394 are from the 15-30 male group. Burials 121, 151, 158A, and 173 are from the 31-44 male group. Burials 103 and 400 are from the 45-55+ male group. Burials 132, 135, 150, and 156A are from the 15-30 female group. Burial 241 is from the 31-44 female group. Burial 162 is from the 45-55+ female group. The tables shows both a z-score and its associated p value. The testing produced only six significant results across three burials (136, 156A, and 162). 
Table 10

Z-Score Results for Mound Burials.

\begin{tabular}{|c|c|c|c|c|c|c|c|c|}
\hline Burial & $\begin{array}{c}\text { Z- } \\
\text { Score } \\
\text { Biceps }\end{array}$ & $\begin{array}{c}\text { P-Value } \\
\text { Biceps }\end{array}$ & $\begin{array}{l}\text { Z-Score } \\
\text { Triceps } \\
\end{array}$ & $\begin{array}{l}\text { P Value } \\
\text { Triceps }\end{array}$ & $\begin{array}{c}\text { Z-Score } \\
\text { Deltoideus }\end{array}$ & $\begin{array}{c}\text { P Value } \\
\text { Deltoideus }\end{array}$ & $\begin{array}{c}\text { Z-Score } \\
\text { Pectoralis }\end{array}$ & $\begin{array}{c}\text { P Value } \\
\text { Pectoralis }\end{array}$ \\
\hline 136 & -0.0408 & 0.484047 & 2.44823 & $0.007179 *$ & 2.19183 & $0.014197^{*}$ & 2.76082 & 0.002883* \\
\hline 137 & -0.0408 & 0.484047 & ND & ND & ND & ND & ND & ND \\
\hline 394 & -0.0408 & 0.484047 & 0.42507 & 0.335418 & -0.25188 & 0.400907 & -0.37647 & 0.353458 \\
\hline 121 & -1.1243 & 0.130507 & 0.35504 & 0.361295 & ND & ND & ND & ND \\
\hline 151 & ND & ND & 0.27615 & 0.391236 & 0.23197 & 0.408308 & 0.60448 & 0.272789 \\
\hline $158 \mathrm{~A}$ & 0.0594 & 0.476476 & 0.27615 & 0.391236 & -1.05674 & 0.145484 & -0.79681 & 0.213016 \\
\hline 173 & -0.5324 & 0.297363 & 0.77584 & 0.21917 & -0.92787 & 0.176963 & ND & ND \\
\hline 103 & 0.0293 & 0.488313 & 0.89654 & 0.185126 & ND & ND & 0.56302 & 0.286717 \\
\hline 400 & 0.0293 & 0.488313 & 0.49232 & 0.31136 & -0.72016 & 0.235762 & 0.29374 & 0.384494 \\
\hline 132 & 1.3788 & 0.083978 & 0.06744 & 0.473132 & -0.2281 & 0.409823 & -0.04445 & 0.482452 \\
\hline 135 & 0.6454 & 0.259334 & -0.8406 & 0.200454 & ND & ND & ND & ND \\
\hline 150 & 0.6454 & 0.259334 & 0.06227 & 0.475281 & -0.37216 & 0.354946 & 1.18394 & 0.118226 \\
\hline $156 \mathrm{~A}$ & -0.8214 & 0.205823 & ND & ND & 4.57387 & $<0.00001^{*}$ & 2.65802 & $0.00393^{*}$ \\
\hline 241 & -0.7724 & 0.220057 & 0.47614 & 0.317037 & -0.3549 & 0.361669 & -0.37945 & 0.352344 \\
\hline 162 & ND & ND & ND & ND & 4.38183 & $<0.00001^{*}$ & 1.09201 & 0.137417 \\
\hline
\end{tabular}

Note: Asterisks indicate P-Values with are statistically significant. 


\section{CHAPTER VI: DISCUSSION}

This chapter explores the biomechanical implications of the entheseal data presented in the previous chapter. The conclusions and inferences, although impactful, are limited in scope for two reasons: limited inter-site comparative data and incomplete individual osteological data. Neidich (2014) provides the only source of comparative Mississippian data for the area, which makes these data and conclusion important for future research. Thus, the labor patterns as interpreted from the reactive changes at entheses may be site-specific labor patterns.

Nonetheless, distinct general and specific muscle movement patterns emerged from the data. The chapter discusses the overall, general trends of the data, makes inferences of possible activity patterns based on ethnohistoric accounts, discusses activity patterns, and their implications for a heterarchical social pattern and model for the Dallas Phase (Cobb 2003, Sullivan and Harle 2010, Sullivan and Mainfort 2010).

\section{General Trends}

\section{Male Entheseal Patterns}

Males display three noticeable, general trends. First, the deltoideus, pectoralis major, and triceps brachii all appear to be utilized in tandem because their scoring increases and decreases in very similar ways (v. Figure 2). The pectoralis major and deltoideus scores also follow almost similar trajectories on Figure 2. Triceps brachii may not be working in perfect tandem as the score trajectory is generally flattens with increased age. The flattening has two possible explanations. The men continued to do actions that involved the triceps at a similar rate, which was lower than its other two partner muscles in the middle age. Two, usage of triceps muscle was more ergonomic than the usage of deltoideus and pectoralis major during middle age. This resulted in lower overall middle age scores and a less detectable entheseal changes. Because of 
this patterning, males appear to have a more predictable or specialized pattern of muscle use compared to females (discussed further below). Many of the male scores, deltoideus, pectoralis major, and triceps brachii in particular, appear to be working in tandem. Additionally, the scores, outside of infraspinatus and supraspinatus, all display very low variance and similar patterning. Ethnohistoric sources are consistent with this pattern (Swanton 1979, Hudson 1976). Males and females primarily divided their labor by season. Males were primarily responsible for hunting during the winter season and occasionally fished or helped with limited aspects of agriculture during the warm season. Females, as discussed more fully below, were responsible for a wider range of actions that spanned both seasons, but primarily concerned themselves with agricultural activity during the warmer seasons. They also intensively gathered seasonally available foods like nuts and roots for winter storage and produced pottery.

The second general trend is that the biceps brachii scores were nearly identical across all age groups. Third, infraspinatus and supraspinatus spike within the middle age group and levels off or drops dramatically in old age respectively. The female pattern (see below) displays the opposite pattern. The spike may be an artifact of sample basis. Preservation issues prevented the scoring of many infraspinatus and supraspinatus scapular insertion sites because they attach along the often poorly preserved blade and medial boarder.

Third, all muscles peak during the middle age group and decrease into the older age group. This indicates a sustained or possible increase in physical activities, which utilized those muscles. The decrease is likely due to a reduction in their activity, which can be easily explained by Wolff's Law and general atrophy. Wolff's law states that bone in a healthy person or animal will adapt to the loads under which it is placed. If loading on a particular bone increases, the bone will remodel itself over time to become stronger to resist that sort of loading (Frost 1990, 
Pearson and Lieberman 2004, Ruff et al. 2006). The internal architecture of the trabeculae undergoes responsive changes, followed by secondary changes to the external cortical portion of the bone. The inverse is true as well. If the loading on a bone decreases, the bone will become less dense due to the lack of the stimulus required for continued remodeling (Cowin 1990, Frost 2004, Mullender and Huiskes 1995, Pearson and Liberman 2004). Osseous reactions and structures from increased stress would decrease since they are not used anymore. This would result in a decrease of entheseal development and scores.

\section{Female Entheseal Patterns}

Females display four noticeable patterns. First, the supraspinatus and deltoideus may have worked in tandem. They have a more similar pattern and trajectory than any of the other muscles or muscle groupings; however, this working group only appears in the transition from young to middle age groups. After middle age, the deltoideus continues to rise and is the only muscle to continue rising at a significant rate after middle age in both males and females. Second, the triceps and pectoralis also appear to work in tandem. They share very similar trajectory although different absolute values. The pectoralis major score is absolutely higher than the triceps indicating that their general activity patterns required increased usage of pectoralis major or usage was un-ergonomic

Third, deltoideus is the only muscle to increase continually from young to old ages between both sexes. The increase indicates that women utilized this muscle at an increasing rate throughout life. A particular activity is likely not the cause of this increase. The deltoideus serves primarily as a stabilizing muscle for the glenohumeral joint and shoulder. Thus, most activities that require a stable shoulder would utilize it. The absolute value, in the old age group, is also higher than the male value, but is not significant $(\mathrm{P}=.92034)$; however, a comparison at middle 
age does approach statistical significance $\left(\mathrm{P}_{<.1}=.12114\right)$. This would indicate that females are utilizing their deltoideus more over a lifetime than males, but not within a single age group.

Fourth, all other muscles increase from the young to middle age group and decrease from the middle to old age group. This pattern likely indicates that younger people were either involved in less work, the same type of work at a lesser intensity (perhaps has novices), or not involved in activities at a great enough rate to affect entheseal change. Wolff's law and principles of atrophy can once again explain the decrease. The workload and activity patterns likely shifted from one age group to another in females as well as males.

\section{Intersex Entheseal Patterns}

Two main patterns emerge between the two sex groups. Females at this site do not seem to be doing the same types of activity for their whole lives or even for a large portion. Most previous research has highly correlated increased age with increased EC scores (Henderson et al. 2006; 2010, Palmer et al. 2014, Schlecht 2012, Schrader 2015). This sample does not show this trait. Previous work has largely focused on historic samples with accompanying rough employment records and exact times of the death (Cardoso and Henderson 2010, Milella et al. 2012, Palmer et al. 2014, Villotte et al. 2010). Their samples are also largely lifelong laborers who engaged in a limited range of daily work activities for most of their lives. In Toqua, nearly

all muscles in both sex group peak within middle age and decrease as the individual senesces, which suggests that their intensity or amount of labor decreased at some point during or between the middle and old age groups or those who survived to old age never worked as hard as others who died younger. Toqua does not reflect a population of lifelong laborers, but rather a population with fluid workloads and activity patterns based on age. 
Second, males appear to have a more specialized labor pattern relative to females. Male scores show a much more predictable clustering (Figure 5.2) than female scores. The patterns are much easier to see within the male chart. Female scores, outside of the limited groupings discussed above, present a much more erratic pattern and show relatively less clustering. Ethnohistoric records may support this notion (Hudson 1976, Strachey 1849, Fogelson and Sturtevant 2008). Hunting during the winter season generally preoccupied males while agricultural and domestic concerns occupied females during the warm season. Slight overlaps existed between these two domains of hunting and agricultural or domestic concerns; however, men were not the primary agriculturalists and women were not the primary hunters. They occasionally played small roles within those social domains (e.g. men digging small holes for seeds or fashioning hoes), but never appeared as the primary actors within them. The erratic nature of the female chart (Figure 5.3) is very different from the closely clustered scores of the male chart. Thus, females likely engaged in a wider range of activities and had a more generalized labor pattern. The next section discusses these activity patterns and the muscles they likely involved in them.

\section{Possible Activities at the Site of Toqua}

\section{Male Activities}

The focal point of male activity during the cold season was hunting. During the warm season, they focused on fishing. Ethnohistoric records speak to many different techniques employed in both ventures. Various sources document two methods of deer hunting: decoy hunting and surrounding. Le Moyne’s (1565) account states,

"The Indians have a way of hunting deer, which we never saw before. They manage to put on the skins of the largest, which have been taken, in such a manner, with the heads on their own heads, so that they can see out through the eyes as through a mask. Thus 
accoutered they can approach close to the deer without frightening them. They take advantage of the time the animals come to drink at the river, and, having their bow and arrows all ready, easily shoot them."

Some accounts show a slight variation in which the hunter would use only the head. Romans (1771) reports,

"They (the Chickasaw) hunt like all their neighbors with the skin and frontal bone of a deer's head, dried and stretched on elastic chips; the horns they scoop out very curiously, employing so much patience on this, that such a head and antlers often do not exceed ten or twelve ounces. They fix this on the left hand and imitating the motions of a deer in sight, they decoy them with sure shot.”

Romans (1771) also report that Native hunters got so good at this technique that other hunters would mistake them for real deer and accidently shoot them.

Historic reports also document many different fishing techniques. They used a variety of techniques including bow and arrow, weirs, spearing, poisoning, netting, hooks, and traps. Beverley (1705) describes an ancient weir,

"They make a dam of loose stone, where there is plenty at hand, quite across the river leaving one, two, or more spaces or tunnels for the water to pass through. At the mouth of which they set a pot of reeds wove in the form of a cone, whose base is about three foot... into which the swiftness of the current carries the fish and wedges them so fast that they cannot possibly return.”

Remains of rock fish weirs remain today and were noted by various historical travelers (Haywood 1823, Myer 1928). Adair (1775) also recounts Native fishermen using spears, “...striking large fish out of their canoes, with long sharp pointed green canes, which are well bearded and hardened in the fire. In the Savannah River, I have often accompanied them in killing sturgeons with those green swamp harpoons...” Lawson (1860) also recounts the use of a bow and arrow, "The youth and Indian boys go fishing in the night. One holding a lightwood 
torch and the other has a bow and arrows. The fire directing him to see the fish and he shoots them with arrows."

Few accounts of fishing using hooks exist; however, many European chroniclers may have omitted these accounts because it was a familiar technique. Archaeologists around the United States find fishhooks as well. Speck’s (1909) account of the Yuchi Indians states that a similar practice still occurs among Native groups. Strachey (1849) recounts native rods and hooks,

"Their angles are long small rods, at the end whereof they have a cleft to which they line is fastened, and at the line they hang a hook. [The hook is] made either of a bone grated (as they nock their arrows) in the form of a crooked pin, or fish hook, or of the splinter of a bone, and with a thread of the line they tie on bait."

Margry (1875) shows that some groups utilized trot lines,

"These nets are really only lines about six fathoms long. A number of small lines are fastened to these a foot apart. At the end of each line is a fishhook where they put a little piece of hominy dough or a little piece of meat... The end of the line is attached to a canoe. They draw them in two or three times a day...”

\section{Correlations between Male Activity and Biological Data}

Many of the Native hunting activities involved heavy upper body use and particularly involve the complex of tandem muscles: pectoralis, deltoideus, and triceps (Bridges 1990, 1992, 1994). Many of the hunting practices listed above would require actions that involve activation of those muscles. Extension of the radioulnar joint requires the triceps, pectoralis major, and infraspinatus (Biel 2005, Liebman 2013, Manocchia 2008). Horizontal adduction of glenohumeral joint requires deltoid, infraspinatus, pectoralis major, triceps, and supraspinatus (Ibid). Vertical adduction of the glenohumeral joint requires deltoideus, and supraspinatus (Ibid). Flexion of both the glenohumeal and radioulnar joints requires deltoideus, pectoralis major, and 
biceps brachii (Ibid). Lateral rotation requires the deltoid and infraspinatus (Ibid). The abovementioned motions require synergist activation from other muscles (Ibid); however, the tandem group of muscles (pectoralis major, deltoideus, and triceps brachii) are involved in almost all of the motions. Additionally, all muscles groups spike in middle age, which indicates either an increase from the previous activity pattern or an emphasis on that activity or labor pattern during middle age.

The bow and arrow is an item cross-utilized between Native hunting and fishing practices. Use of a bow would require extension of the radioulnar joint, horizontal and vertical adduction of the glenohumeral joint, flexion of the radioulnar joint, protracted and retracted (in opposing arms) of the glenohumeral joint, and lateral rotation of the glenohumeral joint. Bow usage could explain the tandem muscle usage seen in young age and the advanced emphasis on hunting into middle age. Younger male children may have used the bow but at a lower rate, which ethnohistoric sources verify (Adair 1775, Lawson 1860). Lawson (1860) states that some young bows would fish at night with a bow, but very sources document bow usage outside of men that used them primarily for hunting.

The spike in both infraspinatus and supraspinatus also supports increased bow usage from the younger group to a middle age group. The infraspinatus, in particular, stabilizes the glenohumeral joint and aids in the lateral rotation necessary for stabilizing a bow at full draw (Ertan 2003, 2009, Hennessey and Parker 1990, Martin et al. 1990). The infraspinatus, deltoid, and triceps are key muscles to stabilize the glenohumeral and radioulnar joints. Accurate, dependable shots depend on a straight, locked, and un-rotated elbow joint (Clarys 1990). A good shot also requires a solid anchor point under the chin, which again requires activation of the infraspinatus and supraspinatus. The supraspinatus abducts the pull hand to chest with the aid of 
deltoideus and pectoralis major to stabilize. The peak of infraspinatus and supraspinatus suggests that middle-aged men more often utilized a bow than the younger or older age groups. Additionally, the lower scores in the young age group could imply that, although some bow usage or hunting occurred, a majority of younger males used an improper technique or a different technique than the middle age group; however, there is little comparative data in the 15-30 age group.

Increased fishing activity may also provide an explanation for the spike during middle age at the infraspinatus and supraspinatus. Netting and trotlines seem to be the most readily reported methods of fishing for the area; however, hook fishing undoubtedly occurred due to the indirect evidence of fishing hooks and fish remains at the site. Net fishing, pulling a fish net back into a canoe, and pulling yourself along in a canoe down a trotline are very similar actions to modern day rowing since both involve dragging an object back against the resistance of water (Fenwick 2009, Gerzevic 2011). The action would require flexion and extension of the radioulnar joint, horizontal abduction and adduction of the glenohumeral joint, medial internal rotation of the glenohumeral joint, and retracted adduction of the glenohumeral joint. Medial rotation, retracted adduction, and horizontal adduction, and abduction of the glenohumeral joint are all action unique to netting (Biel 2005, Liebman 2013, Manocchia 2008). Abduction of the glenohumeral joint utilizes the supraspinatus, which peaks during middle age and drops back down in the older age group. The other upper arm actions mainly utilize the deltoideus and pectoralis major, which not only peak during middle age but also are the two highest scores among males. This indicates that males in the middle age group likely engaged in increased fishing, netting, paddling activities. Perhaps younger men were more able or willing to make longer hunting trips during the winter and middle age men focused primarily on summer time 
labor like fishing or small agricultural jobs like digging small holes or making agricultural implements (Le Moyne 1565). Additionally, specialization may exist between men who primarily fish and men who primarily hunt.

Additionally, lithic processing of projectile points and other tools may also explain the suite of entheseal changes since drawing a bow would have likely occurred at a much lower rate than the production of lithic tools. Lithic scatters were also found in domestic structures at Toqua (Cobb and Pope 1998, Polhemus 1985). Men also produced stone blades for hoes, which women used to till and prepare fields during the warm season (Thomas 2001). As evidenced at Toqua, knapping activities likely took place both in and out of domestic contexts and were done by both sexes. Although men appear to be the primary flint knappers, based on their high association with flint knapping kits at this site and others (Cobb and Pope 1998, Polhemus 1985), it is both unlikely and impractical that women simply waited for men to create an expedient tool or sharpen an existing tool.

Flint knapping engages many of the upper limb and wrist muscles. Flint knapping's downward strike requires glenohumeral extension (deltoideus, infraspinatus, pectoralis major, triceps brachii), radioulnar flexion (deltoideus, pectoralis major, biceps brachii), wrist extension, radioulnar extension (deltoideus, infraspinatus, pectoralis major, triceps brachii), and rapid wrist flexion (Williams et al 2010, 2014). Many of these muscles are also engaged in bow and fishing usage so it is difficult to separate them from one another; however, flint knapping may have begun and continued within the middle age group. The infraspinatus and supraspinatus peak during this time and are very low in the younger age group. It is possible that flint-knapping activity increased from the young to middle age group. 
In conclusion, the biological and medical data combine largely to corroborate and to expand previous conceptions of activity patterns (Adair 1775, Bridges 1989, 1990, Romans 1771, Speck 1909, Swanton 1975). The biological data is limited in scope because it only reflects a group of upper arm muscles and these activities engage a wider, synergistic group of muscles than the ones selected for this study; however, many of these muscles are heavily involved in prehistoric and protohistoric fishing and hunting methods. Bow usage and fish netting techniques, aside from some technological advances among professional archers and commercial anglers, are still very similar to their prehistoric counterparts (Colclough et al. 2002, Kooi 1991, 1998, Wardle 1986). The data suggest that men engaged in a more limited set of activities that emphasized bow usage, in both hunting and fishing, and various types of fishing like netting and trotlines.

\section{Female Activities}

Female activity patterns focused on various agricultural work including tilling, planting, weeding, pest control, and harvest. Native tilling practices, although similar in goal, were different in technique. They did not have conventional, modern shovels or agricultural implements. Men fashioned small hoes for the women to use in the initial tilling or hilling of the ground. Harriot (1893) describes the implements as, “...a foot long and about a few inches in breadth... [They] only break the upper part of the ground to raise up the weeds, grasses and old stubs of corn stalks with their roots.” He further states that women did their tilling sitting down. He describes the men's instruments as more similar to a hoe or mattocks. Strachey (1849) states that women and young children used these same tools to weed their fields a few times a year.

Planting involved another tool: a digging stick. Smith (1884) recounts native planting techniques, "In this place they dig many holes... They used to make with a crooked piece of 
wood being scraped on both sides in fashion of a gardener's paring iron. They put into these holes 4 or 5 kernels of their wheat (corn) and two beans...” Harriot (1849) states that men primarily used the digging sticks; however, some regional variance is noted in other accounts (Smith 1907, Le Moyne 1565).

Women were also involved in a variety of food preparation and culinary activities. A common staple among many Native groups was a various forms of hominy. Speck (1909) recounts hominy techniques,

"To make this the grains of corn, when dry, are removed from the cob and pounded in the mortar until they are broken up. These grits and the corn powder are then scooped out of the mortar and boiled in a pot with water... powdered hickory nuts, or marrow or meat may be boiled to vary its taste.”

Grinding raw food like corn kernels and nuts appear to be the focus of their culinary activities since they used many nuts and wild roots for flour and other bases for breads (Adair 1775, Foreman 1932, MacCauley 1887). They also utilized acorn and hickory nuts for their oil. Adair (1775) recorded the process to produce nut oil,

"They gather a number of hickory nuts, which they pound with a round stone... When they are beat fine enough, they mix them with cold water... The other part is an oily, tough, thick, white substance called by the traders hickory milk, and by the Indians the flesh or fat of hickory nuts."

Lastly, women were the primary producers of domestic utility items like ceramics, textiles, etc. (Swanton 1975). Unlike lithic tools, ceramics likely had a finite window during which women constructed them (du Pratz 1758, Thomas 2001). Ceramic vessels involve a long production sequence including gathering and preparing clay, collecting and preparing shell temper, mixing the paste, and applying any final decoration or surface treatments before and after firing. Summer is the likely time of pottery production in the American Southeast during 
the Mississippian since shell resources are readily available (Ibid). Pottery production in the Southeast took two primary forms: smaller pinch pots/plates and coil method for larger volume vessels. Dumont (1753) recounts pottery production,

"The industry of these Indian girls and women is admirable... After having gathered the earth suitable for this kind of work, and having well cleansed it, they take shells which they grind and reduce... they mix this very fine dust with the earth which they have provided... they knead it with the hands and feet, forming a dough of which they make rolls 6 or 7 feet long... Should they wish to fashion a dish or a vessel they take one of these rolls, and holding down one end with the thumb of the left hand, they turn it around with admirable swiftness and dexterity forming a spiral.”

\section{Correlations between Female Activity and Biological Data}

The most interesting trend among female entheseal scores is deltoideus. It continues to trend upward throughout life and is the only muscle between both sexes to display that trait. All other muscles peak during the middle age group and then drop within the older age group. The continued upward trend of deltoideus may be correlated to the likely more generalized and less specialized activity pattern of females according to ethnohistoric accounts. The deltoideus is

involved in a variety of upper arm movements: radioulnar and glenohumeral flexion, horizontal abduction and adduction, and glenohumeral abduction, lateral external rotation, medial internal rotation.

No matter their age, females engaged in types of labor that continually utilize the deltoideus. Two explanations could explain this phenomenon. First, female labor patterns, throughout the young and old age groups, increase in intensity at the deltoideus. Second, female labor patterns continue to utilize the deltoideus at the same rate; however, cumulative stress continues to accrue throughout life. The second seems like the most likely conclusion. Ethnohistoric sources state that women and young children were the primary agriculturists 
among Native groups of the area (Strachey 1849). It is very likely that many females continued to do some type of agricultural work into old age.

The patterns of the other muscle also support this notion. With the exception of pectoralis, all muscles only drop very slightly from the middle to old age groups. No scapulae preserved from women of this older age group so the true entheseal values for this group is unknown. The other muscles (triceps, biceps, and supraspinatus) only dip slightly after middle age. It is very likely that many women continued a similar, but slightly reduced labor pattern from the middle age group. Ethnohistoric accounts state that older women cared for the crop and even chased off crows and other would be predators of their crops (Adair 1775). Although not as directly involved in agriculture as before, they were nonetheless involved.

Additionally, older woman may have transitioned to focus more on food preparation rather than agriculture, which may also provide an explanation for the increase in deltoideus throughout life. The deltoideus, biceps brachii, and supraspinatus are all involved in the medial rotation, lateral rotation, and radioulnar flexion (Biel 2005, Liebman 2013, Manocchia 2008) that characterizes grinding corn, acorn, or hickory nuts for hominy and nut oil respectively. The biceps brachii and supraspinatus level out from middle age to old age and the deltoideus continues to rise. Therefore, there may have been an activity pattern shift from middle to old age. Younger women and children may have focused on food procurement and agricultural maintenance. Older women may have focused more on food preparation and other culinary activities.

Another interesting trend is the decrease of triceps brachii from the middle to old age group. This drop may correlate with the above general pattern of older woman transitioning to focus on food preparation and culinary activities. The ethnohistoric and bioarchaeological record 
documents tumpline usage (Arten and Lowry 2011, Castro et al. 2016, Molleson 2007, Kahl and Smith 2000, Tiesler 2013). Typical tumpline usage involved a band across the user’s forehead and upper chest area or clavicle area. Scoring for clavicular entheses included various ligament and tendon attachments likely affected by tumpline usage. Pectoralis major, deltoideus, and triceps brachii are the muscles most involved in tumpline usage. Users supported the load on their back with an elevated, adducted glenohumeral joint and an extended radioulnar joint (Castro et al. 2016, Kaneda et al. 1999, Molleson 2007, Stevenson and Bossi 2001). The elevated and adducted shoulders mainly uses muscles not investigated here; however, the flexed radioulnar joint utilizes both pectoralis major and triceps brachii. Additional strain potentially placed on the clavicular region of women engaged tumpline usage might explain the higher absolute EC scores of pectoralis major relative to triceps brachii and further explain increased deltoideus scores throughout life.

Thus, agriculture, food preparation, culinary duties, and production of domestic goods appear to be a lifelong concern and endeavor for most women; however, not all women would have followed this pattern. Various studies (Cobb 2003, Mainfort 2012, Sullivan 2001, 2006, Sullivan and Harle 2012, Sullivan and Rodning 2001) used mortuary patterning to show that women were able to hold positions of power and be chiefs. Additionally, Trocolli (2002) and Perdue (1998) cite ethnohistoric sources that not only support Native women in positions of power but also express their dismay and lack of understanding concerning the androcentric European power structure.

\section{Inter-Individual Variance between Males and Females}

The trends found within the inter-individual variance figures (8-13) are intriguing. First, males have more intra-sexual variance than females. More females consistently show a scoring 
pattern similar to the mean average for their age group. Many females are at or below the mean line; however, there is much more variance within the male group. There are certainly female outliers; however, male’s deviance from the average line occur at a higher rate. The higher degree of variance could indicate two things. One, males may have had more personal autonomy within their activity patterns or had access to multiple labor patterns. The ethnographic evidence does marginally support this by stating that men hunted and fished; however, little detail exists concerning whether the same men both hunted and fished. Therefore, there is little reason to believe that, in most cases, the same men were responsible for both fishing and hunting.

Second, the most variance from the mean pattern for females is within the middle age group and for males within the old age group. Additionally, two males in the old age group closely mirror the female entheseal pattern. This may indicate a split in male activity patterns at old age. The other males in the old age group that do not follow the pattern of the other two have a pattern that closely mimics entheseal scores found in the young male group. Perhaps some older males transitioned to a teaching role for younger males while other males pursued different activities.

Overall, there appears to be a higher degree of variance than the ethnohistoric record would indicate. Ethnohistoric sources, with a few exceptions, largely indicate that sex was the biggest determining factor for labor patterns. This appears to be true for the young and middle age groups for both sexes since they largely cluster in similar ways within their sex groups. Figures 5.4-5.9 likely indicate that, although a typical activity pattern existed for males and females, there was some variance from this pattern and a wider array of actions were available to both males and females. 


\section{Implications for Patterns within a Heterarchy}

The above biological and ethnohistoric data indicate that men and women at Toqua, and the Dallas Phase and Late Mississippian in general, had distinct activity and labor patterns. Women's activity patterns, based on the above-discussed entheseal scores and patterns, focused on the labor-intensive summer and growing season. Men’s activity patterns probably focused on the winter and hunting season; however, both participated in some labor during opposing times of year. Their seasonal labor patterns and new mortuary patterning analysis (Franklin et al. 2010, Sullivan and Harle 2010, Sullivan and Rodning 2010) indicates the possibility that power relationships within and outside of this site are more horizontally than vertically complex.

Early attempts at understanding Mississippian power structures through a chiefdom style model may downplay the diverse and variable power structures at play in Toqua and other major mount settlements in SE Tennessee (Pauketat 2007, Wilson 2007). Additionally, it may also be of even less use at smaller sites (Boudreaux 2007, Mainfort and Fisher-Carroll 2010, Franklin et al 2010). New ideas about Mississippian social and cultural organization in the Southeast are numerous and attempt to incorporate a more nuanced and complex view of power, culture, and structure (Cobb 2003, King 2004, Pauketat 2007, Sullivan 2001; 2006, Sullivan and Rodning 2010). Labor and activity patterns are intertwined with the power and structure since what you do within a society often defines what you mean to it and how you are perceived.

Sullivan and Harle (2010) argue, based on ethnohistoric evidence from Cherokee groups that the types of social distinctions and “classes” we see reflected in mortuary pattern were a difference of degree and not of kind so that social roles were of different types and not based on hierarchical classes. Power relationship within the Dallas phase and this site may have been more horizontally than vertically complex. They argue that the sphere of interactions at other 
Mississippian period site like Fain's and Ledford Island were of differing kinds more so than of degrees. In another article, Sullivan and Mainfort (2010) argues for “...segmentary kinship structures and notions of contextualized and overlapping power heterarchies rather than the strict, primarily vertical relations of hierarchies inherent in the chiefdom model.”

Trocolli (2002) and Perdue (1998) cite ethnohistoric records indicating that women did hold power as both chiefs and as heads of heads of kin groups. Sullivan (2001, 2006), and Sullivan and Rodning (2001) suggest that the mortuary patterning at SE Appalachian Mississippian town is similar to early Cherokee towns. Older women were buried in domestic structures and male leaders in or near community buildings. Toqua and the biological data presented here reflect this pattern. Cobb (2003) sums it up by saying, "Individuals and interest groups often did hold superordinate positions that were hierarchical, and the reproduction of hierarchy involved both material and ideological dimensions. Yet people also assumed multiple identities that extended to gender, clan, and age group affiliations. These social roles provided alternative frameworks for the negotiation of power relationship acted out daily on stages within the household and other venues. Such arenas did not necessarily involve the direct intervention of chiefs or elite positions that we traditionally link to status and institutionalized power.”

The mortuary patterning at Ledford Island displayed these abstract ideas of heterarchy. Sullivan and Harle (2010) speak about two distinct burial locations at Ledford Island: the mound and the plaza. Both locations are places of power, privacy, and publicity but for different reason. Neither place is inherently more or less powerful; however, they certainly possess differing types of power. Burial within a mound or within a structure on a mound is public and has possible religious and communal significance since all can see the mound, but the burial itself and the rituals within are private. On the other hand, burial within the plaza has not only public 
significance but also likely social or domestic power. Sullivan and Harle (Ibid) suggest that these two power structures are horizontally complex rather than vertically complex. Both have equal importance but for different reasons.

In the same way, labor patterns at Toqua can fit into a complex heterarchical power structure. The activity patterns were different yet equally important to subsistence. Both males and females contributed in different ways and in different levels of intensity at distinct times of year: women during the summer and growing season and men during the winter and hunting season. Some ethnohistoric sources (Adair 1775, Le Moyne 1565, Strachey 1849) characterized men as lazy or not as industrious as women, who seemingly worked year round; however, ethnocentrism and limited knowledge of different power structures may have limited their conclusions. Men were not lazy relative to women. Men and women likely operated under different social pressures and provided in very different, yet equally acceptable ways.

The z-score data, although limited in scope, tentatively supports the heterarchical model of Sullivan and Harle (2010). The z-scores of mound burials demonstrate very little variance from the mean relative to their age and sex cohorts. This result indicates that upper arm labor and activity patterns were not a defining characteristic between the potential elites buried within the mound and those buried within the village; however, Toqua's dataset is incomplete because the plaza burials were unavailable for analysis since Barnes did not curate the burials after excavation (Polhemus 1985). If hierarchy was present, activity or labor patterns appear not to be the defining variable in the vertical social complexity of the site. Social power more than likely existed on a spectrum and was not purely hierarchical or heterarchical (Cobb 2003, Pauketat 2007, Thomas 2001). People, even in modern society, often occupy roles with differing status within different social situations and circumstances. It would be naïve to assume a strict 
hierarchy or heterarchy model for Mississippian societies given the radical subsistence and social/political changes associated with the adaptation of/increase in year round sedentism. Aspects of cosmology and religion linked many subsistence activities, hunting and agriculture in particular. Men sang hunting songs and performed hunting rituals. In this way, social structures and ritual interwove with activity patterns. Social structuring and patterning affected their activities, which in turn produced real, quantifiable biological impact in the form of entheseal reaction, development, and regression. Biology, culture, and power structures are intrinsically connected. The heterarchical mortuary patterning, burial in distinct yet public places, also appears in labor patterns. In the same way, two distinct, yet equally important times of subsistence appear during winter and summer. Each is important for different reasons and connected to different groups. The biological data supports the ethnohistoric accounts of distinct labor patterns and the distinct labor patterns integrate into a heterarchical power interpretation. Labor and activity patterns are just one aspect of the power structures in play at Toqua and the Mississippian phase in SE Tennessee. 


\section{CHAPTER VII: CONCLUSION}

In conclusion, this thesis explored a comparative analysis of mechanical stress indicators (EC) of the shoulder by sex and social role/status (as defined by mortuary treatment) within one large Dallas Phase site in SE Tennessee: Toqua (40MR6). It also assessed the results relative to the recent suggestion that the Dallas Phase had a heterarchical power structure (Franklin et al. 2010, Mainfort 2010, Sullivan and Harle 2010, Sullivan and Rodning 2010, Sullivan 2006). EC data explored division of labor within the site, which corroborated ethnohistoric sources regarding typical male and female seasonal roles. EC data also tentatively supported the recent heterarchical power claims, although additional, more robust testing outside of the shoulder/upper arm would be necessary to confirm unequivocally this assumption.

This study also added to the body of EC and activity reconstructions in three meaningful ways. First, the study did not find a distinct correlation of increased entheseal score with age. Previous studies highly linked increased age with increased EC scores (Henderson et al 2006; 2010, Palmer et al. 2014, Schlecht 2012); however, the patterns of this population do not follow this trend. In nearly every muscle, except for female deltoideus, the scores peak in the middle age group and then decrease in the old age group. The pattern in the previous studies show increased scores with increased age; however, the populations of previous studies cited and Toqua's population are very different. Previous studies largely focused on populations of lifelong, historic-era laborers with a limited set of activities. The results from Toqua suggest that this was not the case at Toqua. The population at Toqua appears to have had a much more fluid work and labor pattern than previous historic-era studies.

Second, the above results offer tentative support for the recent assertion of horizontal power patterns within the Dallas Phase (Mainfort 2010, Sullivan and Harle 2010, Sullivan and 
Rodning 2010, Sullivan 2006). The results suggest that activity patterns, at least those confined to muscles in the upper arm and shoulder were not a defining attribute of status within Toqua. Additional testing of entheses outside of the shoulder may prove that mound burials were exempt from certain types of lower body labor that those buried in the village were not. The low number of statistically significant z-score (six total entheses across 15 mound burials) indicate that those buried in the mounds engaged in upper limb activities of a similar type and intensity as those buried within the village and domestic contexts. The z-scores tentatively support the notion that activity patterns were not a defining characteristic in the creation or maintenance of power structure and patterns within Toqua.

Lastly, the biological data helps to corroborate the ethnohistoric accounts of male and female seasonal activity divisions. Ethnohistoric accounts, since European males created them, have inherent, intrinsic biases. The above results, to the extent possible, support ethnohistoric accounts of male and female seasonal labor patterns. It supports that females had a wider range of activities ranging from domestic and agricultural responsibilities and were most active during the summer and planting season. It also supports that men had a more specialized labor pattern focused more on hunting and fishing subsistence activities.

This study is not meant to be a definitive study of activity patterns within the Dallas Phase. Further research could include correlating pathological data with entheseal data to ask questions about whether or not some people were exempted or expected/allowed to do less work than their healthy counterparts. Further research could also include an expansion of studied entheses to include lower limb entheses to obtain a better data on squatting or kneeling activities. This investigation into labor patterns and mechanical stress indicators serves as a launch point 
for future studies on mechanical stress and activity patterns/recreations within Southeastern Tennessee during the Mississippian and as a comparative sample to other periods. 


\section{REFERENCES}

Adair, J., \& Braund, K. E. H. (1775). The history of the American Indians: University of Alabama Press.

Ardren, T., \& Lowry, J. (2011). The travels of Maya merchants in the ninth and tenth centuries AD: investigations at Xuenkal and the Greater Cupul Province, Yucatan, Mexico. World Archaeology, 43(3), 428-443. https://doi.org/10.1080/00438243.2011.607613

Bass, W. M. (2005). Human osteology: A laboratory and field manual of the human skeleton.

Benjamin, M., Evans, E., \& Copp, L. (1986). The histology of tendon attachments to bone in man. Journal of Anatomy, 149, 89.

Benjamin, M., Kumai, T., Milz, S., Boszczyk, B., Boszczyk, A., \& Ralphs, J. (2002). The skeletal attachment of tendons - tendon 'entheses'. Comparative Biochemistry and Physiology Part A: Molecular \& Integrative Physiology, 133(4), 931-945.

Bense, J. A. (1994). Archaeology of the southeastern United States: Paleoindian to World War I.

Betsinger, T. K. (2002). The interrelationship of status and health in the Tellico Reservoir: A biocultural analysis.

Beverley, R. (1705). The history and present state of Virginia: A new edition with an introduction by Susan Scott Parrish. UNC Press Books.

Biel, A. (2014). Trail guide to the body: A hands-on guide to locating muscles, bones and more. Books of Discovery.

Boudreaux, E. A. (2007). The archaeology of Town Creek. University of Alabama Press.

Bridges, P. S. (1989). Changes in activities with the shift to agriculture in the southeastern United States. Current Anthropology, 385-394. doi: https://doi.org/10.1086/203756

Bridges, P. S. (1992). Prehistoric arthritis in the Americas. Annual Review of Anthropology, 6791. https://doi.org/10.1146/annurev.anthro.21.1.67

Bridges, P. S. (1994). Vertebral arthritis and physical activities in the prehistoric southeastern United States. American Journal of Physical Anthropology, 93(1), 83-93. https://doi.org/10.1002/ajpa.1330930106

Brooks, S., \& Suchey, J. M. (1990). Skeletal age determination based on the os pubis: A comparison of the Acsádi-Nemeskéri and Suchey-Brooks methods. Human Evolution, 5(3), 227-238. https://doi.org/10.1007/bf02437238 
Buikstra, J. E., \& Ubelaker, D. H. (1994). Standards for data collection from human skeletal remains: Proceedings of a seminar at the Field Museum of Natural History.

Butler, B. M., \& Welch, P. D. (2006). Leadership and polity in Mississippian society. (Vol. 33): Southern Illinois Univ.

Cardoso, F. A., \& Henderson, C. (2010). Enthesopathy formation in the humerus: Data from known age-at-death and known occupation skeletal collections. American Journal of Physical Anthropology, 141(4), 550-560. https://doi.org/10.1002/ajpa.21171

Chapman, J. (1985). Tellico archaeology: 12,000 years of Native American history. [Norris, Tenn.]: Tennessee Valley Authority ; Knoxville, Tenn. : Distributed by the University of Tennessee Press, 1985.

Chirot, D. (1986). Social change in the modern era. Harcourt.

Clarys, J., Cabri, J., Bollens, E., Sleeckx, R., Taeymans, J., Vermeiren, M., Voss, G. (1990). Muscular activity of different shooting distances, different release techniques, and different performance levels, with and without stabilizers, in target archery. Journal of Sports Sciences, 8(3), 235-257. https://doi.org/10.1080/02640419008732149

Cobb, C. R. (2003). Mississippian chiefdoms: How complex?. Annual Review of Anthropology, 63-84. https://doi.org/10.1146/annurev.anthro.32.061002.093244

Cobb, C. R., \& Butler, B. M. (2016). Mississippian plazas, performances, and portable histories. Journal of Archaeological Method and Theory, 1-27. https://doi.org/10.1007/s10816-016-9281-3

Cook, D., \& Dougherty, S. (2001). Row, row, row your boat: Activity patterns and skeletal robusticity in a series from Chirikof Island, Alaska. Paper presented at the American Journal of Physical Anthropology.

Cowin, S. (1990). Structural adaptation of bones. Applied Mechanics Reviews, 43(5S), S126S133. https://doi.org/10.1115/1.3120791

de Morgues, J. L. M. (1875). Narrative of Le Moyne: An artist who accompanied the French expedition to Florida under Laudonnière, 1564: James R. Osgood.

du Pratz, A. S. L. P. (1758). Histoire de la Louisiane (Vol. 3).

Dumont de Montigny, L. (1753). Historical memoire on Louisiana, Part 1. Survey of federal archives in Louisiana. (Translated by Olivia Blanchard.) Baton Rouge: Louisiana. State University. (Copy housed in Hill Memorial Library.) US Gulf shrimp fishery, 117. 
Dutour, O. (1986). Enthesopathies (lesions of muscular insertions) as indicators of the activities of Neolithic Saharan populations. American Journal of Physical Anthropology, 71(2), 221-224. https://doi.org/10.1002/ajpa.1330710209

Emslander, H. C., Sinaki, M., Muhs, J. M., Chao, E. Y., Wahner, H. W., Bryant, S. C., Eastell, R. (1998). Bone mass and muscle strength in female college athletes (runners and swimmers). Paper presented at the Mayo Clinic Proceedings.

Enlow, D. (1976). The remodeling of bone. Year Book of Physical Anthropology, 20, 19-34.

Ertan, H. (2009). Muscular activation patterns of the bow arm in recurve archery. Journal of Science and Medicine in Sport, 12(3), 357-360. https://doi.org/10.1016/j.jsams.2008.01.003

Ertan, H., Kentel, B., Tümer, S., \& Korkusuz, F. (2003). Activation patterns in forearm muscles during archery shooting. Human Movement Science, 22(1), 37-45. https://doi.org/10.1016/s0167-9457(02)00176-8

Fenwick, C. M., Brown, S. H., \& McGill, S. M. (2009). Comparison of different rowing exercises: Trunk muscle activation and lumbar spine motion, load, and stiffness. The Journal of Strength \& Conditioning Research, 23(2), 350-358. https://doi.org/10.1519/jsc.0b013e3181b07334

Fogelson, R., \& Sturtevant, W. (2004). Handbook of North American Indians, Volume 14: Southeast. US Independent Agencies and Commissions.

Foreman, G. (1932). Indian removal: The emigration of the five civilized tribes of Indians (Vol. 2). University of Oklahoma Press.

Franklin, J. D., Price, E. K., Langston, L. M., Sullivan, L. P., \& Mainfort Jr, R. C. (2010). The mortuary assemblage from the Holliston Mills site, a Mississippian town in upper east Tennessee. Mississippian mortuary practices: Beyond hierarchy and the representationist perspective. University of Alabama Press, Tuscaloosa, 250-269.

Frost, H. (1990). Skeletal structural adaptations to mechanical usage (SATMU): 1. Redefining Wolff's law: The bone modeling problem. The Anatomical Record, 226(4), 403-413. https://doi.org/10.1002/ar.1092260402

Frost, H. M. (2003). Bone's mechanostat: A 2003 update. The Anatomical Record Part A: Discoveries in Molecular, Cellular, and Evolutionary Biology, 275(2), 1081-1101. https://doi.org/10.1002/ar.a.10119

Galera, V., \& Garralda, M. (1993). Enthesopathies in a Spanish medieval population: Anthropological, epidemiological, and ethnohistorical aspects. International Journal of Anthropology, 8(4), 247-258. https://doi.org/10.1007/bf02442159 
Gerževic, M., Strojnik, V., \& Jarm, T. (2011). Differences in muscle activation between submaximal and maximal 6-minute rowing tests. The Journal of Strength \& Conditioning Research, 25(9), 2470-2481. https://doi.org/10.1519/jsc.0b013e3181fb4111

Goodman, A. H., \& Leatherman, T. L. (1998). Traversing the chasm between biology and culture: An introduction. Building a new biocultural synthesis: Political-economic perspectives on human biology, 3-42.

Hamrick, M., McPherron, A., Lovejoy, C., \& Hudson, J. (2000). Femoral morphology and crosssectional geometry of adult myostatin-deficient mice. Bone, 27(3), 343-349. https://doi.org/10.1016/s8756-3282(00)00339-2

Harriot, T. (1893). Narrative of the first English plantation of Virginia. B. Quaritch.

Havelková, P., Hladík, M., \& Velemínský, P. (2013). Entheseal changes: Do they reflect socioeconomic status in the early medieval central European population? (MikulčiceKlášteřisko, Great Moravian Empire, 9th-10th century). International Journal of Osteoarchaeology, 23(2), 237-251. https://doi.org/10.1002/oa.2294

Havelková, P., Villotte, S., Velemínský, P., Poláček, L., \& Dobisíková, M. (2011). Enthesopathies and activity patterns in the Early Medieval Great Moravian population: Evidence of division of labour. International Journal of Osteoarchaeology, 21(4), 487504. https://doi.org/10.1002/oa.1164

Hawkey, D. (1988). Use of upper extremity enthesopathies to indicate habitual activity patterns [Thesis]. Department of Anthropology. Tempe: Arizona State University.

Hawkey, D. E., \& Merbs, C. F. (1995). Activity-induced musculoskeletal stress markers (MSM) and subsistence strategy changes among ancient Hudson Bay Eskimos. International Journal of Osteoarchaeology, 5(4), 324-338. https://doi.org/10.1002/oa.1390050403

Haywood, J. (1823). The Natural and Aboriginal History of Tennessee, Up to the First Settlements Therein by the White People. G. Wilson.

Heinonen, A., Sievänen, H., Kannus, P., Oja, P., \& Vuori, I. (2002). Site-specific skeletal response to long-term weight training seems to be attributable to principal loading modality: A pQCT study of female weightlifters. Calcified Tissue Iternational, 70(6), 469-474. https://doi.org/10.1007/s00223-001-1019-9

Hems, T., \& Tillmann, B. (2000). Tendon entheses of the human masticatory muscles. Anatomy and Embryology, 202(3), 201-208. https://doi.org/10.1007/s004290000107

Henderson, C., Mariotti, V., Pany-Kucera, D., Perréard-Lopreno, G., Villotte, S., \& Wilczak, C. (2010). Scoring entheseal changes: Proposal of a new standardized method for fibrocartilaginous entheses. Paper presented at the Poster presented at the 18th European Meeting of the Paleopathology Association, Vienna, Austria 23rd-26th of August. 
Henderson, C., Mariotti, V., Pany-Kucera, D., Villotte, S., \& Wilczak, C. (2013). Recording specific entheseal changes of fibrocartilaginous entheses: Initial tests using the Coimbra method. International Journal of Osteoarchaeology, 23(2), 152-162. https://doi.org/10.1002/oa.2287

Henderson, C., Mariotti, V., Pany-Kucera, D., Villotte, S., \& Wilczak, C. (2015). The New 'Coimbra Method': A Biologically Appropriate Method for Recording Specific Features of Fibrocartilaginous Entheseal Changes. International Journal of Osteoarchaeology. https://doi.org/10.1002/oa.2477

Henderson, C. Y., \& Alves Cardoso, F. (2013). Special issue entheseal changes and occupation: Technical and theoretical advances and their applications. International Journal of Osteoarchaeology, 23(2), 127-134. https://doi.org/10.1002/oa.2298

Henderson, C. Y., Mariotti, V., Pany-Kucera, D., Perréard-Lopreno, G., Villotte, S., \& Wilczak, C. (2012). The effect of age on entheseal changes at some fibrocartilaginous entheses. American Journal of Physical Anthropology, 147(S54), 163. https://doi.org/10.1002/oa.2287

Hennessy, M., \& Parker, A. (1990). Electromyography of arrow release in archery. Electromyography and Clinical Neurophysiology, 30(1), 7-17.

Hudson, C. M. (1976). The Southeastern Indians. Knoxville: University of Tennessee Press, 1976.

Huijing, P. A. (1999). Muscle as a collagen fiber reinforced composite: A review of force transmission in muscle and whole limb. Journal of Biomechanics, 32(4), 329-345. https://doi.org/10.1016/s0021-9290(98)00186-9

Jeske, R. J. (1999). World-Systems Theory, Core-Periphery interactions, and elite economic exchange in Mississippian societies. World-Systems Theory in Practice: Leadership, Production, and Exchange, 203-221. https://doi.org/10.5195/jwsr.1996.85

Jones, A. (2001). Archaeological theory and scientific practice (Vol. 1): Cambridge University Press.

Jurmain, R., Cardoso, F. A., Henderson, C., \& Villotte, S. (2012). Bioarchaeology's holy grail: The reconstruction of activity. A Companion to Paleopathology, 531-552. https://doi.org/10.1002/9781444345940.ch29

Kahl, K. E., \& Ostendorf Smith, M. (2000). The pattern of spondylosis deformans in prehistoric samples from west-central New Mexico. International Journal of Osteoarchaeology, 10(6), 432-446. https://doi.org/10.1002/1099-1212(200011/12)10:6\%3C432::aidoa535\%3E3.0.co;2-v 
Kaneda, E., Yamauchi, M., Ohwatari, N., Lee, J.-B., \& Kosaka, M. (1999). Haulage methods in different areas of Nepal and the health condition of the porters in Kathmandu. 熱帯医学 Tropical Medicine, 41(1), 55-64.

Kennedy, K. (1983). Morphological variations in ulnar supinator crests and fossae as identifying markers of occupational stress. Journal of Forensic Sciences, 28(4), 871-876. https://doi.org/10.1520/jfs11594j

Kennedy, K. A., \& İşcan, M. Y. (1989). Reconstruction of Life from the Skeleton. Alan R. Liss.

King, A. (2004). Deciphering Etowah's Mound C: The construction history and mortuary record of a Mississippian burial mound. Southeastern Archaeology, 153-165.

Lawson, J. (1860). The history of Carolina [OH Perry \& Company] Printed by Strother \& Marcom.

Lewis, T. M. N., Lewis, M. D. K., \& Sullivan, L. P. (1995). The prehistory of the Chickamauga Basin in Tennessee (Vol. 2). Univ. of Tennessee Press.

Lieber, R. L., \& Friden, J. (2000). Functional and clinical significance of skeletal muscle architecture. Muscle \& Nerve, 23(11), 1647-1666. https://doi.org/10.1002/10974598(200011)23:11\%3C1647::aid-mus1\%3E3.3.co;2-d

Liebman, H. L. (2012). Anatomy of Fitness: Core. Hinkler.

Lieverse, A. R., Bazaliiskii, V. I., Goriunova, O. I., \& Weber, A. W. (2013). Lower limb activity in the Cis-Baikal: Entheseal changes among middle Holocene Siberian foragers. American Journal of Physical Anthropology, 150(3), 421-432. https://doi.org/10.1002/ajpa.22217

Little, K. (1973). Bone Behaviour. Academic Press.

Lovejoy, C. O., Meindl, R. S., Pryzbeck, T. R., \& Mensforth, R. P. (1985). Chronological metamorphosis of the auricular surface of the ilium: A new method for the determination of adult skeletal age at death. American Journal of Physical Anthropology, 68(1), 15-28. https://doi.org/10.1002/ajpa.1330680103

Lovejoy, C. O., \& Trinkaus, E. (1980). Strength and robusticity of the Neandertal tibia. American Journal of Physical Anthropology, 53(4), 465-470. https://doi.org/10.1002/ajpa.1330530402

Lyon, E. A. (1996). A new deal for southeastern archaeology. University of Alabama Press. MacCauley, C. (1887). The Seminole Indians of Florida. University Press of Florida. 
Maier, M., Steinborn, M., Schmitz, C., Stäbler, A., Köhler, S., Veihelmann, A., Refior, H.-J. (2001). Extracorporeal shock-wave therapy for chronic lateral tennis elbow-prediction of outcome by imaging. Archives of Orthopaedic and Trauma Surgery, 121(7), 379-384. https://doi.org/10.1007/s004020100261

Mainfort Jr, R. C., Fisher-Carroll, R., \& Sullivan, L. P. (2010). Temporal changes in mortuary behavior: Evidence from the Middle and Upper Nodena sites, Arkansas. Mississippian mortuary practices: Beyond hierarchy and the representationist perspective. University of Alabama Press, Tuscaloosa, 128-144.

Mainfort, R. C., \& Sullivan, L. P. (2010). Mississippian mortuary Practices: Beyond hierarchy and the representationist perspective. University Press of Florida.

Manocchia, P. (2008). Anatomy of exercise: A trainer's inside guide to your workout. Firefly Books Ltd.

Margry, P. (1875). 1886. Découvertes et établissements des Français dans l'ouest et dans le sud de l'Amérique Septentrionale (1614-1754). Paris.

Mariotti, V., Facchini, F., \& Belcastro, M. G. (2007). The study of entheses: Proposal of a standardised scoring method for twenty-three entheses of the postcranial skeleton. Collegium Antropologicum, 31(1), 291-313.

Martin, P. E., Siler, W. L., \& Hoffman, D. (1990). Electromyographic analysis of bow string release in highly skilled archers. Journal of Sports Sciences, 8(3), 215-221. https://doi.org/10.1080/02640419008732147

Meyers, M. (2017). Social integration at a frontier and the creation of Mississippian social identity in southwestern Virginia. Southeastern Archaeology, 1-12. https://doi.org/10.1080/0734578x.2017.1292075

Meyers, M. S. (2015). The role of the Southern appalachian Mississippian frontier in the creation and maintenance of chiefly power. Archaeological perspectives on the southern Appalachians: A multiscalar approach, 219.

Milella, M., Giovanna Belcastro, M., Zollikofer, C. P., \& Mariotti, V. (2012). The effect of age, sex, and physical activity on entheseal morphology in a contemporary Italian skeletal collection. American Journal of Physical Anthropology, 148(3), 379-388. https://doi.org/10.1002/ajpa.22060

Montgomery, E., Pennington, C., Isales, C. M., \& Hamrick, M. W. (2005). Muscle-bone interactions in dystrophin-deficient and myostatin-deficient mice. The Anatomical Record Part A: Discoveries in Molecular, Cellular, and Evolutionary Biology, 286(1), 814-822. https://doi.org/10.1002/ar.a.20224 
Moore, H. L. (1994). A geologic trip across Tennessee by interstate 40. Univ. of Tennessee Press.

Mullender, M., \& Huiskes, R. (1995). Proposal for the regulatory mechanism of Wolff's law. Journal of Orthopedic Research, 13(4), 503-512. https://doi.org/10.1002/jor.1100130405

Myer, W. E. (1928). Indian trails of the Southeast. Blue \& Gray Press.

Nagy, B., \& Hawkey, D. (1993). Correspondence of osteoarthritis and muscle use in reconstructing prehistoric activity patterns. Paper presented at the Twentieth Annual Meeting of the Paleopathology Association, April.

Neidich, D. (2014). A comparative study of mechanical stress in the Pre-Columbian Tennessee River Valley. (Master of Science), Illinois State University.

Niinimäki, S. (2011). What do muscle marker ruggedness scores actually tell us? International Journal of Osteoarchaeology, 21(3), 292-299. https://doi.org/10.1002/oa.1134

Nordin, M., \& Frankel, V. H. (2001). Basic biomechanics of the musculoskeletal system. Lippincott Williams \& Wilkins.

Palmer, J., Hoogland, M., \& Waters-Rist, A. (2014). Activity reconstruction of Post-Medieval Dutch rural villagers from upper limb osteoarthritis and entheseal changes. International Journal of Osteoarchaeology. https://doi.org/10.1002/oa.2397

Parham, K. (1987). Toqua skeletal biology: A biocultural approach. The Toqua site: A Late Mississippian Dallas Phase town, 1, 431-552.

Pauketat, T. R. (2007). Chiefdoms and other archaeological delusions. Rowman Altamira.

Pearson, O. M., \& Lieberman, D. E. (2004). The aging of Wolff's “law”: Ontogeny and responses to mechanical loading in cortical bone. American Journal of Physical Anthropology, 125(S39), 63-99. https://doi.org/10.1002/ajpa.20155

Peterson, J. (1998). The Natufian hunting conundrum: spears, atlatls, or bows? Musculoskeletal and armature evidence. International Journal of Osteoarchaeology, 8(5), 378-389. https://doi.org/10.1002/(sici)1099-1212(1998090)8:5\%3C378::aid-oa436\%3E3.0.co;2-i

Polhemus, R. R. (1987). The Toqua Site-40MR6: A Late Mississippian, Dallas Phase Town, Volume I.

Powell, M. L. (1988). Status and health in prehistory: A case study of the Moundville chiefdom.

Pritchard, E. (2009). The construction of the Hiwassee Island mound. TVA archaeology: Seventy-five years of prehistoric site research, edited by Erin Pritchard, 181-209. 
Romans, B., \& Braund, K. E. H. (1771). A concise natural history of East and West Florida: University of Alabama Press.

Ruff, C. (2009). Relative limb strength and locomotion in Homo habilis. American Journal of Physical Anthropology, 138(1), 90-100. https://doi.org/10.1002/ajpa.20907

Ruff, C., Holt, B., \& Trinkaus, E. (2006). Who's afraid of the big bad Wolff?:“Wolff's law” and bone functional adaptation. American Journal of Physical Anthropology, 129(4), 484498. https://doi.org/10.1002/ajpa.20371

Schlecht, S. H. (2012). Understanding entheses: Bridging the gap between clinical and anthropological perspectives. The Anatomical Record, 295(8), 1239-1251. https://doi.org/10.1002/ar.22516

Schrader, S. A. (2015). Elucidating inequality in Nubia: An examination of entheseal changes at Kerma (Sudan). American Journal of Physical Anthropology, 156(2), 192-202. https://doi.org/10.1002/ajpa.22637

Schroedl, G. F. (1998). Mississippian towns in the Eastern Tennessee Valley. Mississippian towns and sacred Spaces: Searching for an architectural grammar. 64-92.

Schroedl, G. F., Boyd Jr, C. C., \& Davis Jr, R. S. (1990). Explaining Mississippian origins in east Tennessee. The Mississippian emergence. Smithsonian Institution Press, Washington, DC, 175-196.

Shaw, C. N., \& Stock, J. T. (2009a). Habitual throwing and swimming correspond with upper limb diaphyseal strength and shape in modern human athletes. American Journal of Physical Anthropology, 140(1), 160-172. https://doi.org/10.1002/ajpa.21063

Shaw, C. N., \& Stock, J. T. (2009b). Intensity, repetitiveness, and directionality of habitual adolescent mobility patterns influence the tibial diaphysis morphology of athletes. American Journal of Physical Anthropology, 140(1), 149-159. https://doi.org/10.1002/ajpa.21064

Skedros, J. G., Mason, M. W., \& Bloebaum, R. D. (2001). Modeling and remodeling in a developing artiodactyl calcaneus: A model for evaluating Frost's Mechanostat hypothesis and its corollaries. The Anatomical Record, 263(2), 167-185. https://doi.org/10.1002/ar.1094

Sládek, V., Berner, M., Galeta, P., Friedl, L., \& Kudrnová, Š. (2010). Technical note: The effect of midshaft location on the error ranges of femoral and tibial cross-sectional parameters. American Journal of Physical Anthropology, 141(2), 325-332. https://doi.org/10.1002/ajpa.21153

Smith, B. D. (1984). Mississippi expansion: Tracing the historical development of an explanatory model. Southeastern Archaeology, 13-32. 
Smith, B. D. (2007). The Mississippian emergence. University of Alabama Press.

Smith, B. D. (2014). Mississippian settlement patterns: Studies in archeology. Academic Press.

Smith, J. (1884). Travels and works, ed. Edward Arber and AG Bradley (Edinburgh, 1910), 1, 149.

Smith, M. O. (2003). Beyond palisades: The nature and frequency of late prehistoric deliberate violent trauma in the Chickamauga Reservoir of East Tennessee. American Journal of Physical Anthropology, 121(4), 303-318. https://doi.org/10.1002/ajpa.10232

Speck, F. G. (1909). Ethnology of the Yuchi Indians. U of Nebraska Press.

Steponaitis, V. P. (1978). Location theory and complex chiefdoms: A Mississippian example. Mississippian settlement patterns. 417-453.

Stevenson, J. M., \& Bossi, M. L. L. (2001). Technical evaluation report. Soldier mobility: Innovations in Load Carriage System Design and Evaluation.

Strachey, W. (1849). The history of travaile into Virginia Britannia: Expressing the cosmographie and comodities of the country, together with the manners and customs of the people (Vol. 6).

Sullivan, L., \& Prezzano, S. (2001). A conscious Appalachian archaeology. Archaeology of the Appalachian highlands., 323-331.

Sullivan, L. P. (2001). Archaeology of the Appalachian highlands: Univ. of Tennessee Press.

Sullivan, L. P., \& Rodning, C. B. (2010). 6 residential burial, gender roles, and political development in late prehistoric and early cherokee cultures of the Southern Appalachians. Archeological Papers of the American Anthropological Association, 20(1), 79-97.

Thomas, L. (2001). The gender division of labor in Mississippian households. Archaeological studies of gender in the southeastern United States, 29-56.

Tiesler, V. (2013). The bioarchaeology of artificial cranial modifications: New approaches to head shaping and its meanings in Pre-Columbian Mesoamerica and beyond (Vol. 7). Springer Science \& Business Media.

Villotte, S., Castex, D., Couallier, V., Dutour, O., Knüsel, C. J., \& Henry-Gambier, D. (2010). Enthesopathies as occupational stress markers: Evidence from the upper limb. American Journal of Physical Anthropology, 142(2), 224-234. https://doi.org/10.1002/ajpa.21217

Villotte, S., Churchill, S. E., Dutour, O. J., \& Henry-Gambier, D. (2010). Subsistence activities and the sexual division of labor in the European Upper Paleolithic and Mesolithic: 
Evidence from upper limb enthesopathies. Journal of Human Evolution, 59(1), 35-43. https://doi.org/10.1016/j.jhevol.2010.02.001

Villotte, S., \& Knüsel, C. (2013). Understanding entheseal changes: Definition and life course changes. International Journal of Osteoarchaeology, 23(2), 135-146. https://doi.org/10.1002/oa.2289

Wallerstein, I. (1974). The rise and future demise of the world capitalist system: Concepts for comparative analysis. Comparative studies in society and history, 16(04), 387-415. https://doi.org/10.4324/9780203300527_chapter_3.2

Wallerstein, I. (2011). The modern world-system I: Capitalist agriculture and the origins of the European world-economy in the sixteenth century, with a new prologue (Vol. 1). Univ of California Press.

Weinman, J. P., \& Sicher, H. (1955). Bone and bones. Fundamentals of bone biology. The American Journal of the Medical Sciences, 215(1), 113. https://doi.org/10.1097/00001888-194705000-00025

Weiss, E. (2003). Understanding muscle markers: Aggregation and construct validity. American Journal of Physical Anthropology, 121(3), 230-240. https://doi.org/10.1002/ajpa.10226

Weiss, E. (2009). Sex differences in humeral bilateral asymmetry in two hunter-gatherer populations: California Amerinds and British Columbian Amerinds. American Journal of Physical Anthropology, 140(1), 19-24. https://doi.org/10.1002/ajpa.21025

Williams, E., Gordon, A., \& Richmond, B. (2010). Upper limb kinematics and the role of the wrist during stone tool production. American Journal of Physical Anthropology, 143(1), 134-145. https://doi.org/10.1002/ajpa.21302

Williams, E. M., Gordon, A., \& Richmond, B. G. (2014). Biomechanical strategies for accuracy and force generation during stone tool production. Journal of Human Evolution, 72, 5263. https://doi.org/10.1016/j.jhevol.2014.03.004

Woods, W. I. (2004). Population nucleation, intensive agriculture, and environmental degradation: The Cahokia example. Agriculture and Human Values, 21(2), 255-261. https://doi.org/10.1023/b:ahum.0000029398.01906.5e

Zumwalt, A. (2005). A new method for quantifying the complexity of muscle attachment sites. The Anatomical Record Part B: The New Anatomist, 286(1), 21-28. https://doi.org/10.1002/ar.b.20075 